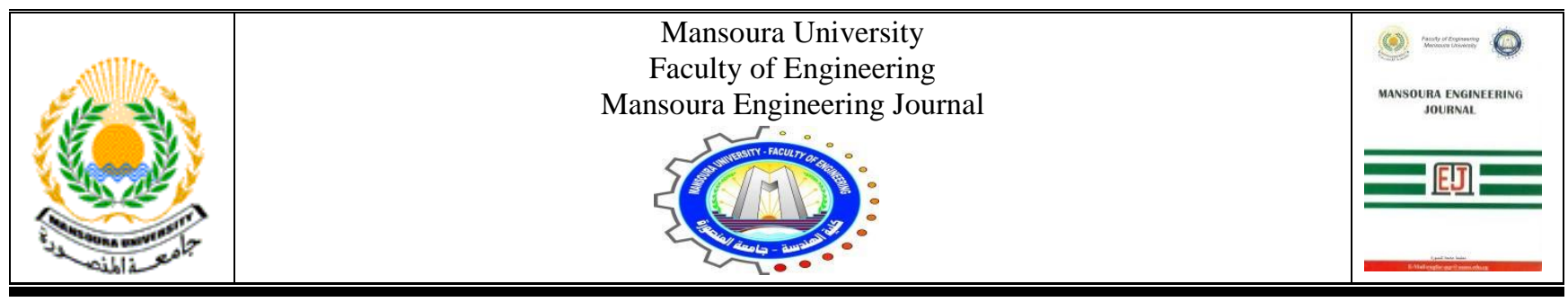

\title{
Approximate static analysis of circular convex cable roof beams in the existence of central and edge rings

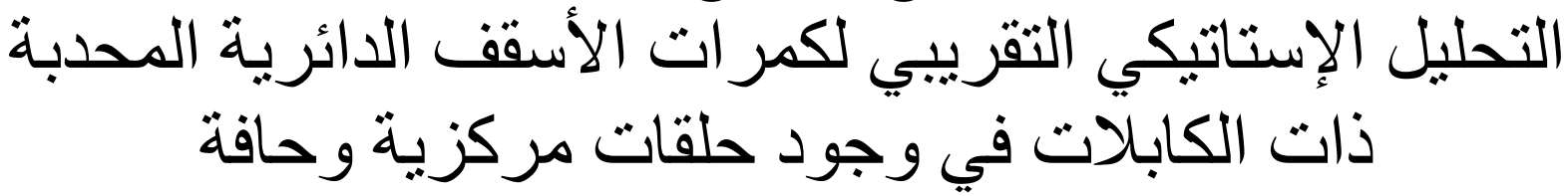

Y. E. Aggag, M. Naguib, S. El Bagalaty, and A. M. Abbas

\begin{abstract}
KEYWORDS:
Tension structures, cables, circular roofs, convex beams, preliminary analysis
\end{abstract}

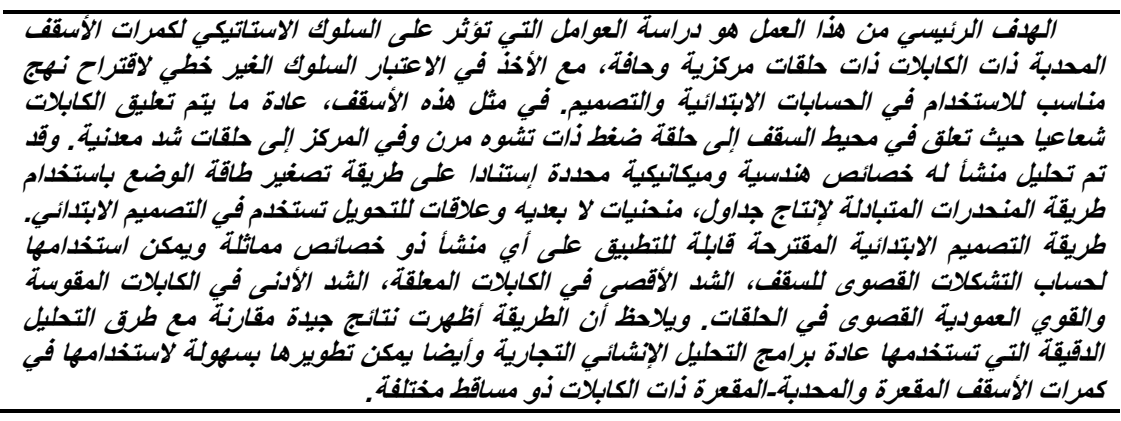

\begin{abstract}
The key objective of the present work is to study the parameters affecting the static behavior of convex cable roof beams with central and edge rings, taking into consideration the nonlinear behavior to propose an appropriate approach for their preliminary calculations and design aspects. In such roofs, the cables are commonly suspended radially and attached at the perimeter of the roof to an elastically deformable compression edge ring and at the center to tension steel rings. A structure with

Received:: 31 May, 2018 - Accepted: 4 July, 2018

Y. E. Aggag, Emeritus Professor in Department of Structural Engineering, Faculty of Engineering, Mansoura University (e-mail: youssefagag@gmail.com).

M. Naguib, Emeritus Professor in Department of Structural Engineering, Faculty of Engineering, Mansoura University (e-mail: naguib2005@yahoo.com).

S. El Bagalaty, Assistant Professor in Department of Structural Engineering, Faculty of Engineering, Mansoura University (e-mail: dr.salah.bagalaty@gmail.com).

A. M. Abbas, Demonstrator in Department of Structural Engineering, Faculty of Engineering, Mansoura University (e-mail: a_m_abbas@ mans.edu.eg).
\end{abstract}

a specific geometrical and mechanical properties has been analyzed based upon the minimization of the total potential energy by the conjugate gradient method to produce nondimensional curves, tables, and transformation expressions used for the preliminary design. The suggested preliminary approach is applicable for any structure with similar characteristics and can be used to determine the maximum roof deformations, maximum tensions of the sagging cables, minimum tensions of the hogging cables, and the maximum normal forces in the rings. It is noted that the method show good results compared to the exact analysis methods commonly used by commercial programs in structural analysis, and can be readily developed to be used for concave, convex-concave cable beam roofs with different plans of view.

\section{INTRODUCTION}

I $\mathrm{N}$ recent decades, cable structures have been considered an economical alternative over traditional portal and conventional structural systems for their mechanical properties and load carrying efficiency. Cable elements work only in pure axial tension and can carry large loads much more than their own weight. Therefore, their 
spacing can be greatly increased to cover long spans without causing stability issues [1]. Also, from the architectural point of view, their lightness offer an infinite number of possibilities for shaping unique and elegant three dimensional roofing forms with rectangular, rhomboid, circular or elliptical plans [2].

Disadvantages also appear as the high geometric nonlinearity of cables is always a challenge to the stability of structures. When a cable subjected to variable loading conditions, it undergoes large movements that increase the difficulty of the analysis and design procedure [3]. Therefore the principle of superposition does not acceptable for such systems, and it is strongly recommended to take the effects of cables flexibility and their large deformations into concern when establishing equilibrium equations [4].

Thus, preliminary techniques are valuable in order to reduce the computational effort exerted in estimation of cable sizes, their pretention forces, initial costs and materials required [5]. Many analytical researches supposed infinitely rigid supports for cable edges, and ignore deformations and flexibility of the supporting structures, i.e., edge rings, stays, and columns. The first effort adopts the former principle for preliminary analysis of cable networks has been carried out by Gero [6]. The method is based on preforming geometrically nonlinear analyses to produce scaling relationships and charts. These relationships are used for transformation of a much larger analysis problem called the prototype to a smaller network denoted as the model. The prototype and the model, should have similar geometries, so that their corresponding characteristics also be similar.

However, studies show that the deformability of the boundary at joints of cable attachments, results a loss in the tension of the cables and a variation in the net deflections [7]. Thus the static and dynamic characteristics of a cable structure will vary depending upon the stiffness of the supporting system. The latter in turn is a function of the element geometry and type of the material used. Useful approximate procedures for certain cases of cable systems have been developed by Talvik [8], Majowiecki, and Zoulas [9]. Also, Szabó et. al. [10] supposed another preliminary method for analysis of cable networks with elliptical plan view, where cable ends are attached to an edge beam. Isabella Vassilopoulou and Charis J. Gantes [11], have been extending the transformation relations that established by Gero [6] to be applicable for circular cable networks supported by an elastically deformable ring beam, taking into consideration the ring stiffness and the curvature of the cables, i.e. sag and rise to span ratios.

The main objective of the present work is to study the static behavior of circular convex cable roof beams, through geometrically nonlinear analyses. Tables and graphs illustrate the response are given in nondimensional form, and represent the guidelines to derive transformation relations used for the preliminary design of such roofs. The analysis is carried out by a FORTRAN computer program based on the minimization of the total potential energy (T.P.E.) of the structure using the conjugate gradient method [12]. Selected examples have been resolved to verify and confirm the results obtained using SAP2000 [13].

\section{MODEL CHARACTERISTICS AND PARAMETRIC STUDIES}

In case of roofs with circular plans, cable beams can be distributed radially and attached at the center to a small steel tension ring and at the perimeter to a compression edge ring commonly made of prestressed concrete with a square or a rectangular cross sections, as shown in Figs. 1(a), (b), (c), and (d) [14]. A study of a convex cable system of the type shown in Fig. 1(b) is presented to determine its static response for variation in particular significant parameters now follows.

These parameters include the cable sizes, pretension forces, and their curvatures. Also the effect of the rigidity and deformability of flexural elements on the behavior are included. The study is carried out considering one variable parameter, and others are constant in each case. The net shown in Fig. 2, with various sections of structural elements shown in Fig. 3, is proposed for the analysis.

To simplify notations and in order to avoid misunderstanding, in case of equal properties for both the sagging and the hogging cables, each of the extensional rigidity, the pretension force, and the cables curvature may be termed as $E A, H$, and $f / L$ respectively.

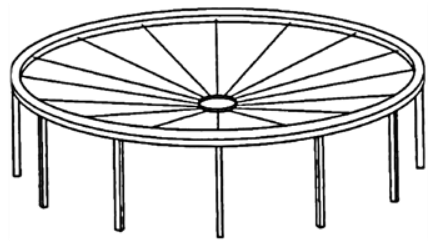

(a)

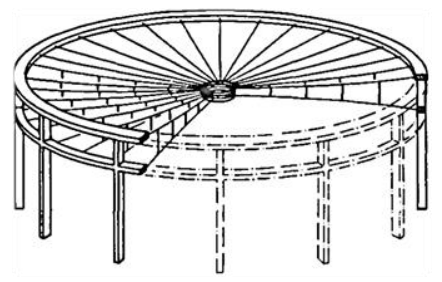

(c)

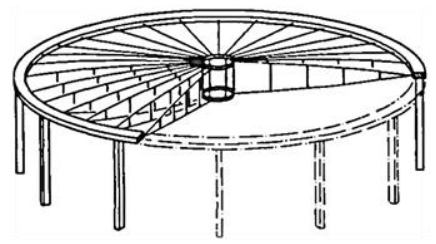

(b)

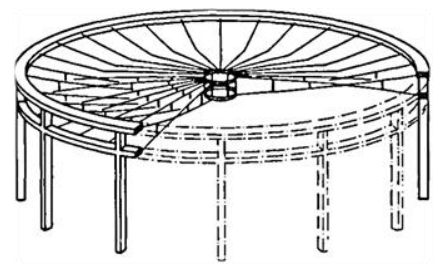

(d)
Fig. 1. Circular cable roofs with cables suspended in radial planes between central tension ring/s and outer edge ring/s: (a) Simply suspended cable roof; (b) Convex cable beam structure; (c) Concave cable beam structure; (d) Convex-concave cable beam structure.

The static analysis is carried out for a cable net having a span of $80 \mathrm{~m}$, sag to span ratio $4 \%$, and rise to span ratio $4 \%$. The net consists of 42 pairs of convex cable beams distributed radially between two steel central rings and a single R.C. edge ring, where the diameters ratio for central to edge rings is considered as $8.0 \%$. The cable beam consists of a dual-cable counter stressed system with properties shown in Table. 1. Both the lower sagging, and the top hogging cables have extensional rigidities of $297.7 \mathrm{MN}$, and the same pretension forces of $570 \mathrm{KN}$. While, the 12 struts are made of steel pipes 
with extensional rigidity of $19.95 \mathrm{MN}$.

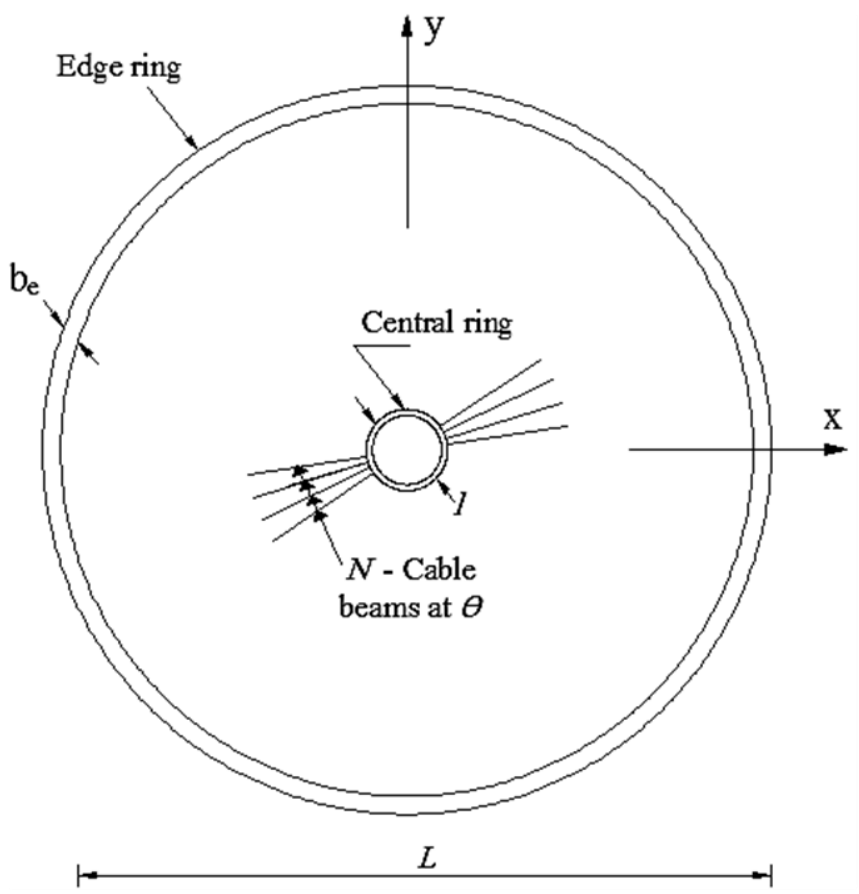

Fig. 2. Plan view of radial convex cable beam structure

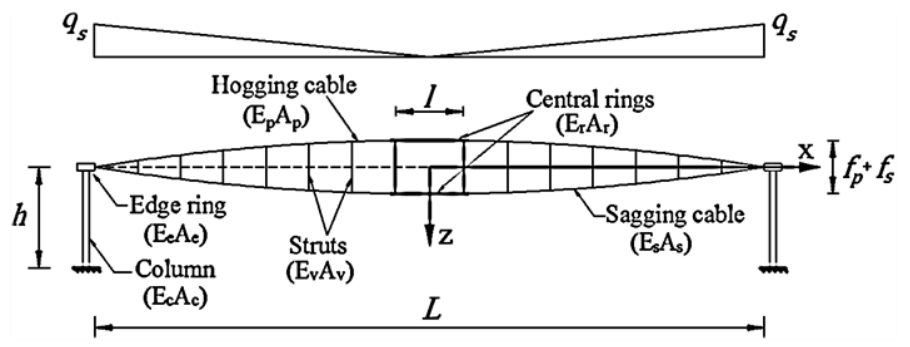

(a)

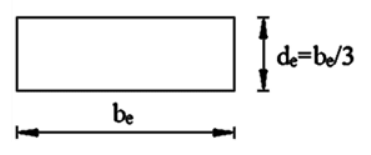

(c)

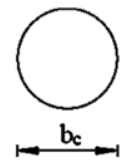

$\mathrm{b}_{\mathrm{T}} / 12$

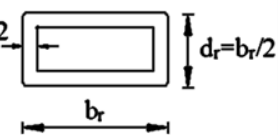

(e)
Fig. 3. Convex cable beam structure: (a) Cross section through the roof; (b) Cross section of the R.C. edge beam; (c) Cross section of the R.C. column; (d) Cross section of the steel central ring.

Table. 2 shows the characteristics of the flexural elements utilized in the analysis. The edge ring has a rectangular reinforced concrete section with extensional rigidity of 49980 MN. While, central rings have a rectangular hollow steel section with extensional rigidity $6699 \mathrm{MN}$. Each cable connection at the edge ring is supported vertically with reinforced concrete columns have circular sections with extensional rigidity of $17102 \mathrm{MN}$. All Columns have a mean height of $10 \mathrm{~m}$ and supposed to be fixed at base.

For circular roofs in which the cable beams radiate out from a centrally suspended tension ring, it is convenient to express the distributed load applied on each beam as a two symmetrically triangular distributed loads with a maximum intensity placed on the upper cable [15]. Uniformly distributed loads used are based on the following values:

- Dead load of the roof $=400 \mathrm{~N} / \mathrm{m}^{2}$ of projected area

- Live loads $=500 \mathrm{~N} / \mathrm{m}^{2}$ of projected area

For the purpose of analysis, the triangularly distributed loads are assumed to be applied as a system of equivalent concentrated forces equally spaced and applied on the joints of the hogging cable.

The obtained results are prepared in a nondimensional formulae for the maximum positive deflection of the net $(w)$, maximum radial deformations of the edge ring $\left(u_{e}\right)$, the minimum hogging cable tension $\left(T_{p}\right)$, the maximum sagging cable tension $\left(T_{s}\right)$, the upper central ring tension $\left(P_{p}\right)$, the lower central ring tension $\left(P_{s}\right)$, the edge ring compression $\left(P_{e}\right)$, and the maximum bending moment at the level of fixed base $\left(M_{b}\right)$.

TABLE 1

PROPERTIES OF CABLES UTILIZED IN THE PARAMETRIC STUDY

\begin{tabular}{l||c}
\hline \multicolumn{2}{|c|}{ STUDY } \\
\hline Cross sectional area,$A\left(\mathrm{~cm}^{2}\right)$ & 18 \\
\hline Modulus of elasticity, $E(\mathrm{MPa})$ & 165500 \\
\hline Pretension force, $H(\mathrm{KN})$ & 570 \\
\hline Weight per unit length, $(\mathrm{N} / \mathrm{m})$ & 140.4 \\
\hline
\end{tabular}

TABLE 2

PROPERTIES OF FLEXURAL ELEMENTS UTILIZED IN THE PARAMETRIC STUDY

\begin{tabular}{l||c||c||c}
\hline \multicolumn{1}{c||}{ Parameters } & Edge ring & Column & $\begin{array}{l}\text { Central } \\
\text { rings }\end{array}$ \\
\hline $\begin{array}{l}\text { Cross sectional area }, A \\
\left(\mathrm{~m}^{2}\right)\end{array}$ & 1.47 & 0.503 & 0.0319 \\
\hline $\begin{array}{l}\text { Modulus of elasticity, } E \\
(\mathrm{MPa})\end{array}$ & 34000 & 34000 & 210000 \\
\hline $\begin{array}{l}\text { Moment of inertia, Ixx } \\
\left(\mathrm{m}^{4}\right)\end{array}$ & 0.06 & 0.0201 & $1.29 \times 10^{-4}$ \\
\hline $\begin{array}{l}\text { Moment of inertia, Iyy } \\
\left(\mathrm{m}^{4}\right)\end{array}$ & 0.54 & 0.0201 & $4.33 \times 10^{-4}$ \\
\hline $\begin{array}{l}\text { Moment of inertia, Izz } \\
\left(\mathrm{m}^{4}\right)\end{array}$ & 0.19 & 0.0402 & $2.99 \times 10^{-4}$ \\
\hline $\begin{array}{l}\text { Weight per unit length, } \\
(\mathrm{KN} / \mathrm{m})\end{array}$ & 36.75 & 12.575 & 2.49 \\
\hline
\end{tabular}

Many study parameters are considered as:

\section{A. Effect of the curvature of cables and the load intensity on the response}

In general, geometric nonlinearity is a principle feature of cable structures analyzing. It is affected by the stiffness of the structure which is a function of the pretension forces, curvature of the cables, and the stiffness of the supporting system [16]. Many researchers suggested that the satisfactory 
stiffness of the cable net will be accomplished if the maximum sag of the sagging cable is within $4 \%$ and $6 \%$ of the span [17].

The beams are analyzed in order to provide insight into the behavior of the system due to the cables curvature under varying loading intensities from $150 \mathrm{~N}$ to $1150 \mathrm{~N}$. Different cases of equal sag and rise to span ratios with $f / L=3 \%, 4 \%$, $5 \%$, and $6 \%$ are considered.

The deformed shape of the structure is sketched in Fig. 4. Also, values of maximum deflections of the net along $\mathrm{z}$ axes, maximum deformations of the edge ring, maximum and minimum cables tensions, and maximum normal forces of rings are plotted in Figs. 6 to 13.
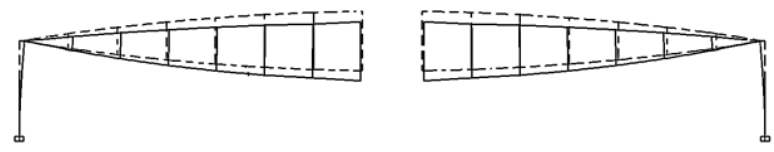

(a) Deformed shape due to pretension forces only
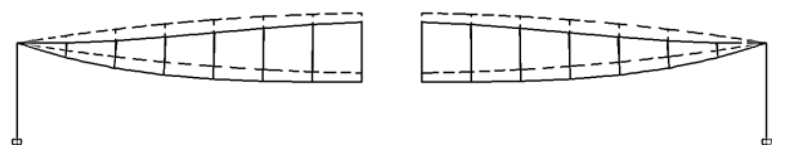

(b) Deformed shape due to the case of dead + live loads
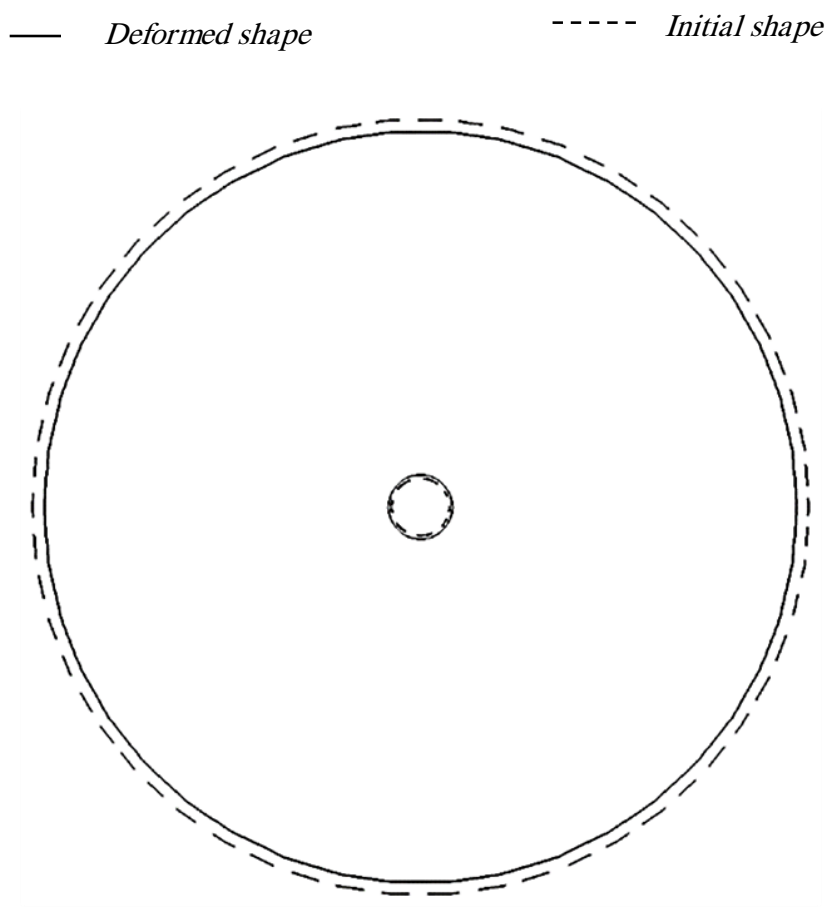

(c) Deformation of rings

Fig. 4. Illustrative sketches of the deformed structure

It is noted that:

1. The system becomes stiffer and responds in less nonlinear manner with increasing of the load intensity and sag/rise to span ratios.

2. The nonlinear response of the cables causes a nonlinear response of the rings.
3. Due to rising loading of the net, the tension change in the sagging cables is much larger than that in the hogging cables, therefore the sagging cables may be properly termed as the primary cables, whilst the hogging cables are called the secondary cables, Fig. 5(a).

4. The tension along a cable slightly increases towards the edge ring, such as the vertical component is increased to balance the increased shear force due to the existing loads, although its horizontal component remains constant.

5. The rate of change in the tensile force of the cables is small from segment to another. Thus, the design of tension for the whole cable can be adopted as the same value without any considerable loss in economy.

6. The principal mode of action of the edge ring is axial compression, while that for both central rings is direct axial tension, Fig. 5(b). Therefore, in the final deformed shape of the net, opposite joints of the edge ring are approaching each other, Fig. 4(c).

7. Increasing the sag/rise to span ratios cause a decrease of the maximum deflections of the net, the maximum tension of sagging cables, tensions of the lower central ring, and compressive force of the edge ring. While, tensions of the upper central ring and hogging cables are increased.

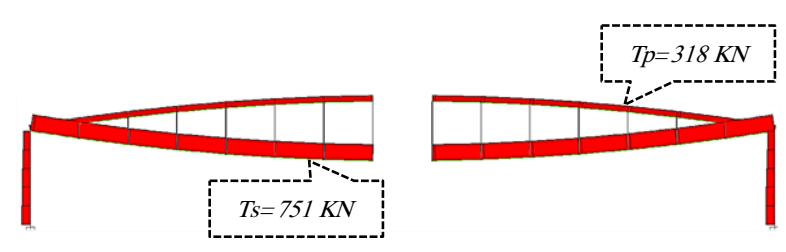

(a) Cable tensions and column compressions

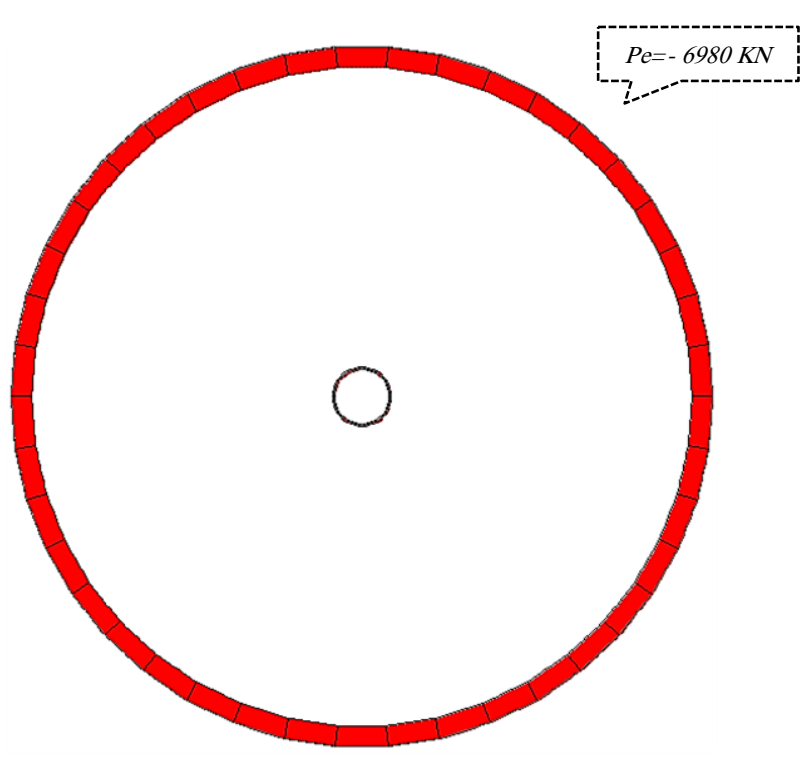

(b) Central ring tensions and edge ring compression

Fig. 5. Sketches of normal forces due to the case of dead + live loads 
With the following figures, Figs. 6 to 13 , the following symbols are used to define the cable curvature case:

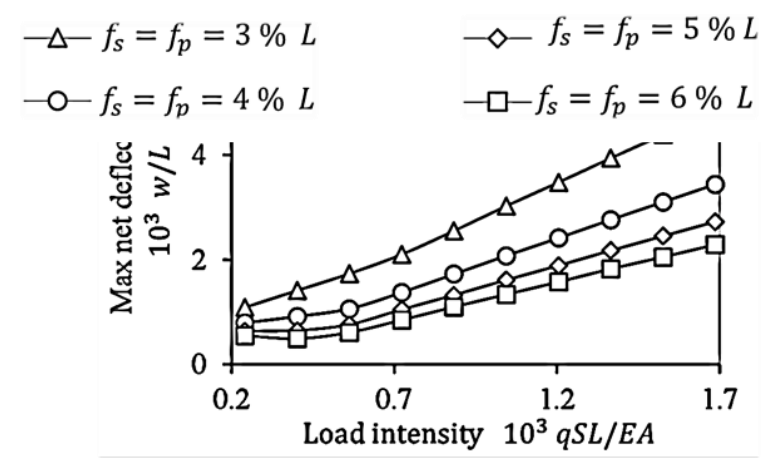

Fig. 6. Variation of maximum net deflections with cables curvature and load intensities

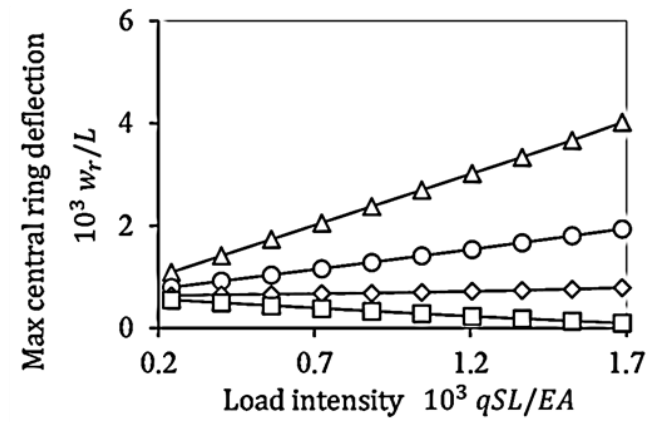

Fig. 7. Variation of central ring deflections with cables curvature and load intensities

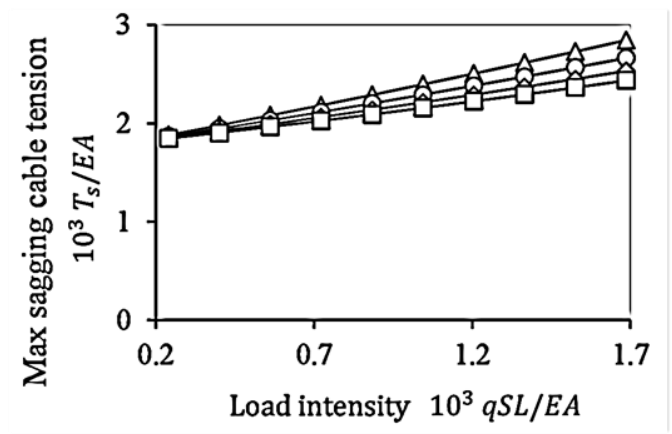

Fig. 8. Variation of sagging cable tensions with cables curvature and load intensities

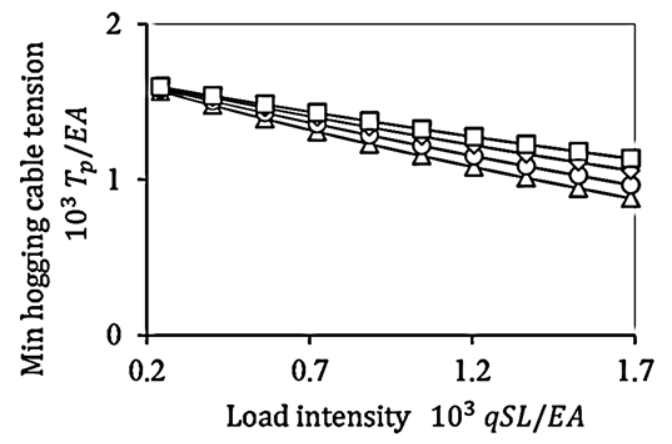

Fig. 9. Variation of hogging cable tensions with cables curvature and load intensities

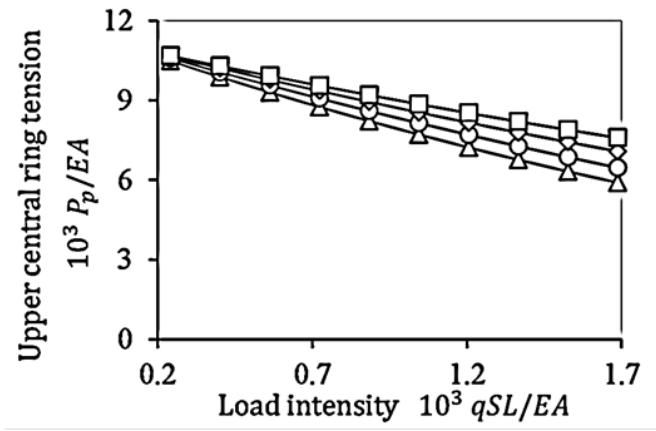

Fig. 10. Variation of upper central ring tensions with cables curvature and load intensities

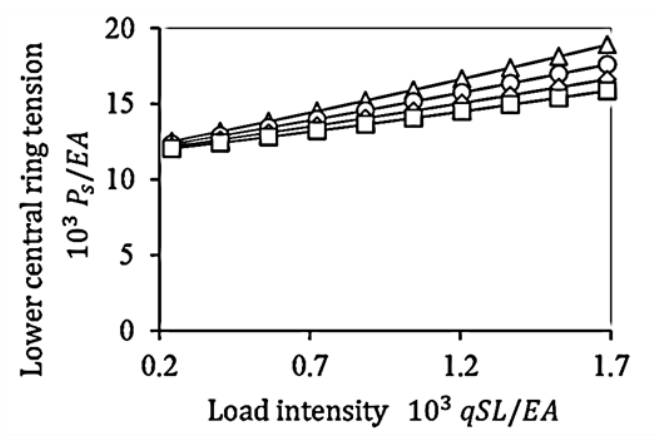

Fig. 11. Variation of lower central ring tensions with cables curvature and load intensities

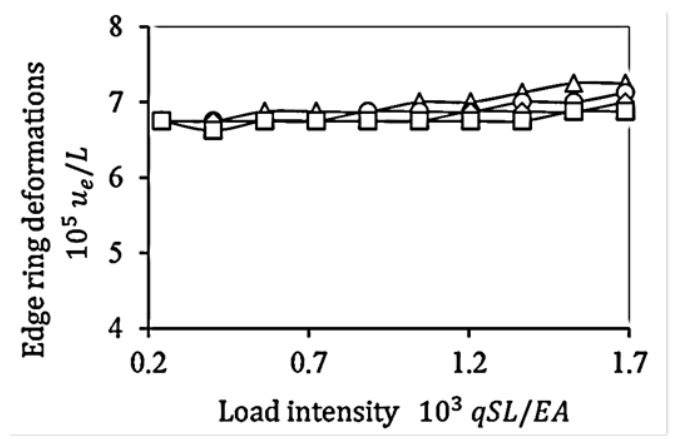

Fig. 12. Variation of edge ring deformations with cables curvature and load intensities

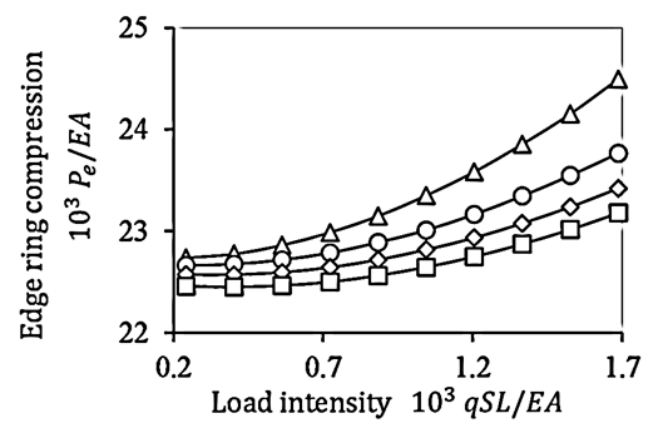

Fig.13. Variation of edge ring compression forces with cables curvature and load intensities 


\section{B. Effect of cable sizes on the response}

In the latter, the analysis is carried out under the load combination of dead + live loads with a uniform intensity of $q$ $=900 \mathrm{~N} / \mathrm{m}^{2}$. The same cable roof is reanalyzed for varying cable sizes ranged from $E A=83 \mathrm{MN}$ to $680 \mathrm{MN}$. Three cases are considered as; Case (1): the extensional rigidity of hogging cables is kept constant at 297.7 MN, while that of sagging cables are varied, Case (2): the extensional rigidity of sagging cables are kept constant at 297.7 MN, while that of hogging cables are varied, Case (3): both of the extensional rigidity of hogging cables and sagging cables are varied.

With reference to Figs. 14 to 19 . We can shortly note that:

1. Increasing sizes of both the hogging cables and/or the sagging cables, results a decrease of the maximum deflections of the net.

2. For Cases (2) and (3), increasing of cable sizes leads to reduce the hogging cable tensions, deformations and compression forces of the edge ring. On the other hand, increasing of cable sizes in Case (1) causes an increase on the same parameters.

3. Sagging cable tensions slightly increase with increasing of cable sizes in Cases (1) and (3), while they decrease with increasing cable sizes in Case (2).

With the following figures, Figs. 14 to 19, the following symbols are used to define the cable size case:

$$
\begin{aligned}
& \multimap \text { Case (1): } E_{p} A_{p} / H=523 \quad \& E_{s} A_{s} / H=\text { variable } \\
& \neg \text { Case (2): } E_{s} A_{s} / H=523 \quad \& E_{p} A_{p} / H=\text { variable } \\
& \multimap \multimap \text { Case (3): } E_{s} A_{s} / H=E_{p} A_{p} / H=\text { variable }
\end{aligned}
$$

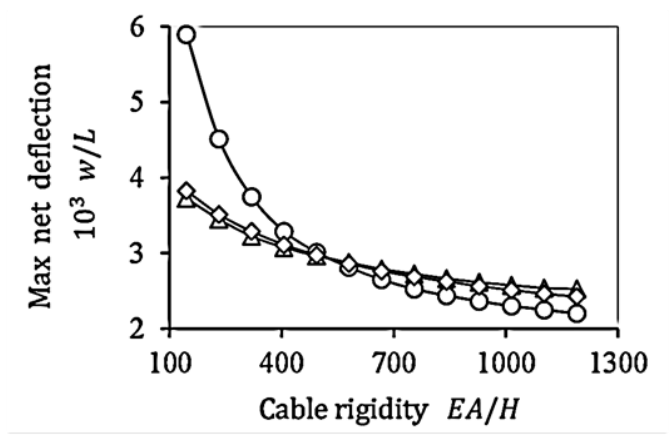

Fig. 14. Variation of maximum net deflections with cable sizes

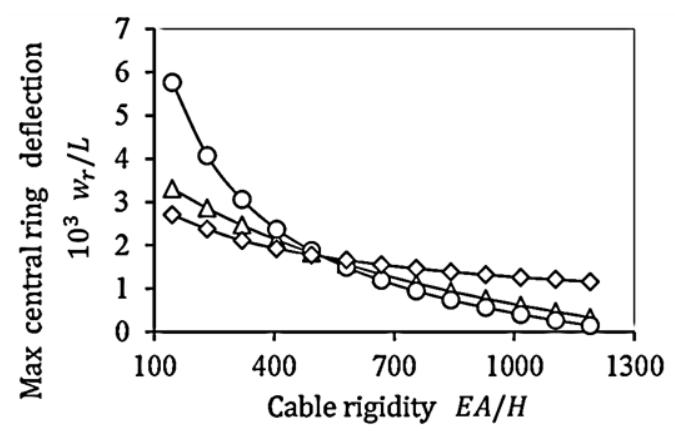

Fig. 15. Variation of central ring deflections with cable sizes

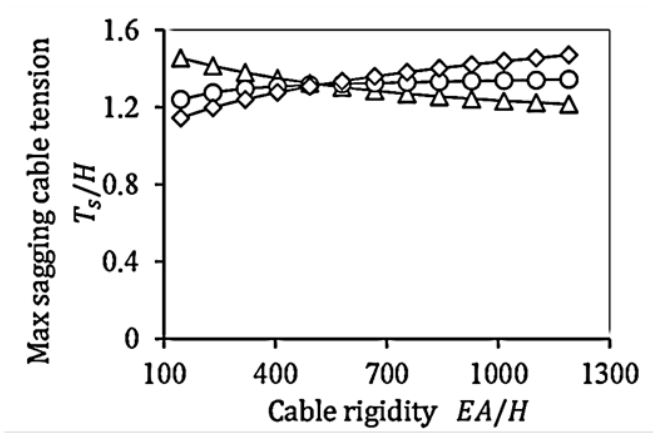

Fig. 16. Variation of sagging cable tensions with cable sizes

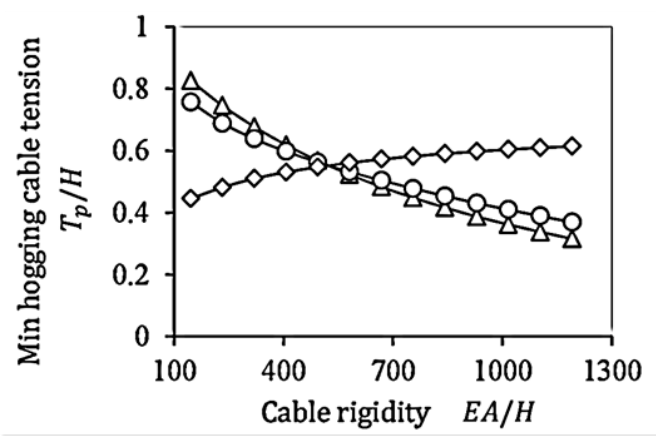

Fig. 17. Variation of hogging cable tensions with cable sizes

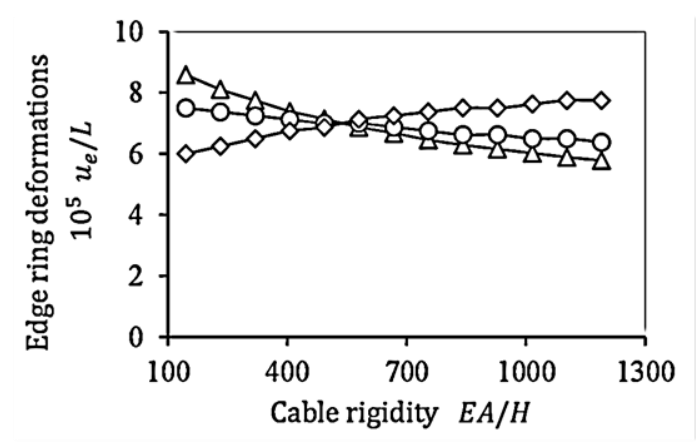

Fig. 18. Variation of edge ring deformations with cable sizes

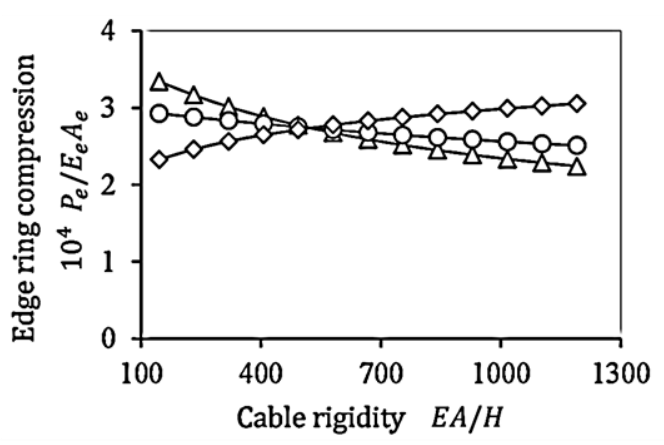

Fig. 19. Variation of edge ring compression forces with cable sizes 


\section{Effect of cable pretension forces on the response}

Selecting the appropriate level of pretension is essential to keep cables always in tension and never become slack to avoid large deformations and formation of flat regions and fluttering due to unsatisfactory stiffness under any load combination [18].

The cable roof is analyzed for three levels of varying pretension forces ranged from $H=300$ to $1200 \mathrm{KN}$. Level (1): the pretension forces of hogging cables are kept constant at $570 \mathrm{KN}$, while that of sagging cables are varied, Level (2): the pretension forces of sagging cables are kept constant at 570 $\mathrm{KN}$, while that of hogging cables are varied, Level (3): both of the pretension forces of hogging cables and sagging cables are varied.

Results of the analysis are plotted in Figs. 20 to 25. Where, the following symbols are used to define the pretension force level:

$$
\begin{aligned}
& -\triangle \text { - Level(1): } H_{p} / E_{p} A_{p}=1.9 \times 10^{-3} \quad \& H_{s} / E_{s} A_{s}=\text { variable } \\
& \text { ○- Level(2): } H_{s} / E_{s} A_{s}=1.9 \times 10^{-3} \quad \& H_{p} / E_{p} A_{p}=\text { variable } \\
& \text { ○-Level(3): } H_{s} / E_{s} A_{s}=H_{p} / E_{p} A_{p}=\text { variable }
\end{aligned}
$$

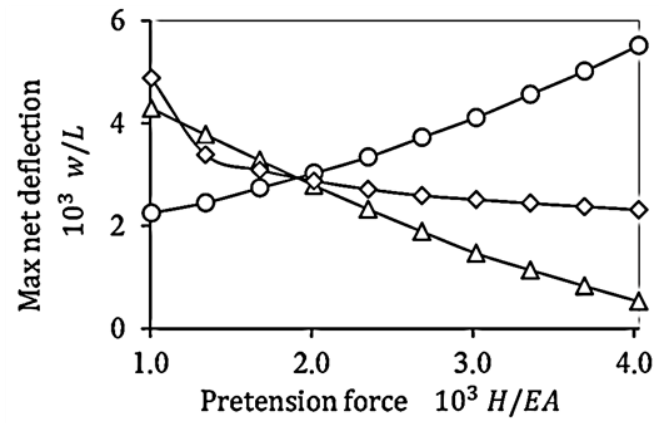

Fig. 20. Variation of maximum net deflections with cable pretension forces

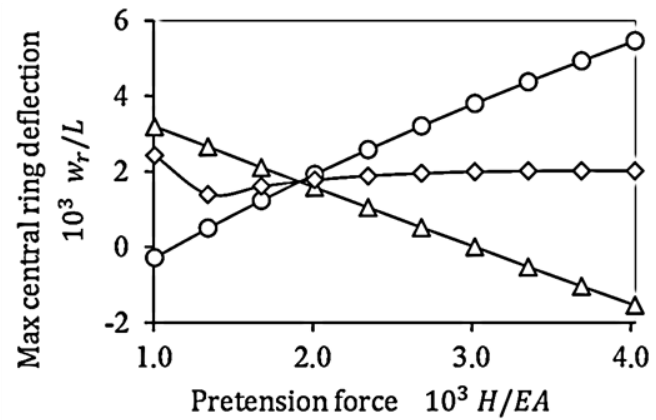

Fig. 21. Variation of central ring deflections with cable pretension forces

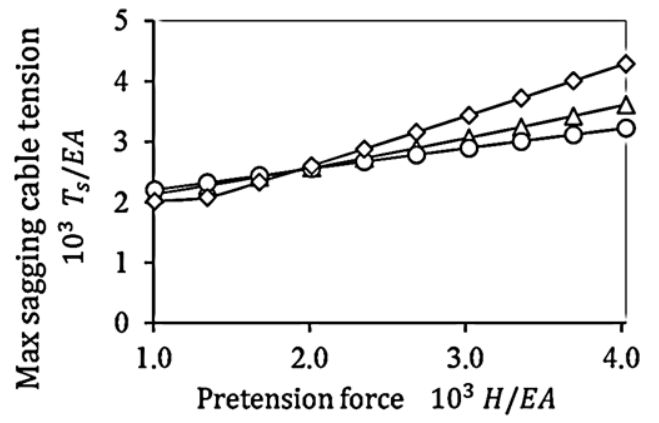

Fig. 22. Variation of sagging cable tensions with cable pretension forces

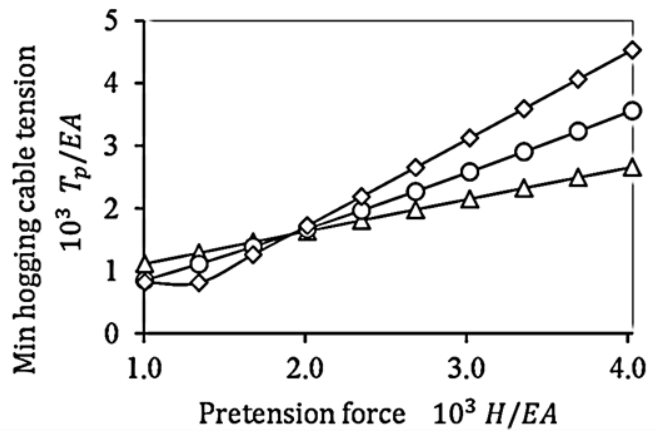

Fig. 23. Variation of hogging cable tensions with cable pretension forces

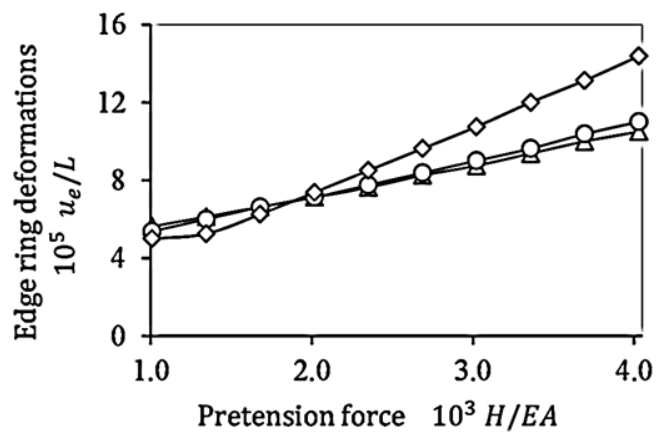

Fig. 24. Variation of edge ring deformations with cable pretension forces

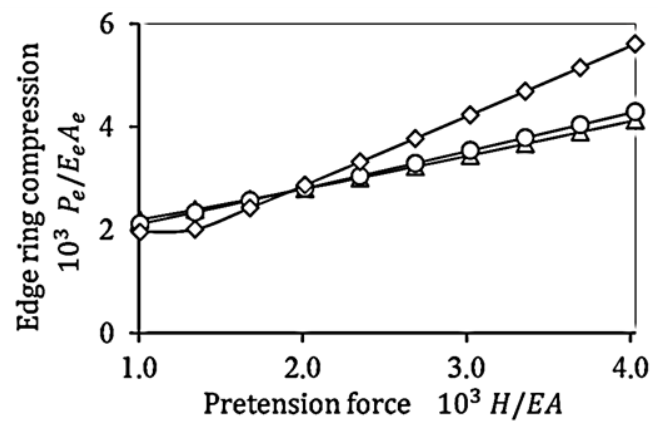

Fig. 25. Variation of edge ring compression forces with cable pretension forces

Generally, increasing of the cable size or its pretension force beyond the required values that keep cables always in tension without slacking causes a defect of utilizing of the cable cross-sectional area and lessen the effect of the pretension force. Hence, it is recommended that the design of cables and their cross-sectional areas are such that the maximum load the cables are expected to carry is less than or equal to $50 \%$ of their breaking strength, [19]. With reference to Figs. 20 to 25 , it is noted that:

1. For Level (1), as the pretension forces of the sagging cables increase, the values of compression forces of the edge ring increase, on the other hand, the maximum deflections of the net decrease and the cable tensions are increased.

2. For Level (2), as the pretension forces of the hogging cables increase, the values of compression forces of the edge ring increase, also, the maximum deflection of the net and the cable tensions are increased.

3. Level (3) generally provides larger values of cable tensions and compression forces of the edge ring. 


\section{Effect of the stiffness of central rings and the diameters ratio on the response}

In case of utilizing radial cable roofs, existence of tension rings leads to a more uniform distribution of cables, allows to use cable units with equal lengths, and reduces the number of cable terminals required. Figs. 26 to 31, show the effect of increasing the stiffness of both upper and lower central rings, $E_{r} A_{r}=1230 \mathrm{MN}$ to $19700 \mathrm{MN}$, on the response for two values of the diameters ratio $\delta=8 \%$ and $25 \%$.

It is observed that, although varying of the stiffness and the diameters ratio affect the radial and vertical deformations of the central rings, it has marginal effects on the subsequent deformations and internal forces of other net elements.

The following symbols are used with Figs. 26 to 31, to define the diameters ratio used:

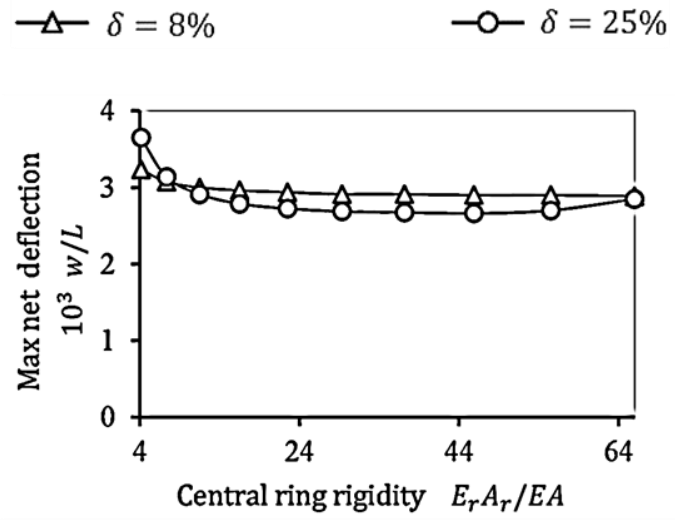

Fig. 26. Variation of net deflections with central rings stiffness and diameters ratio.

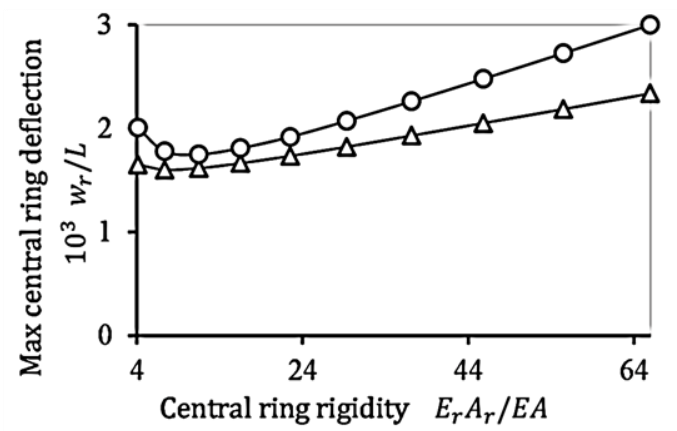

Fig. 27. Variation of central ring deflections with central rings stiffness and diameters ratio.

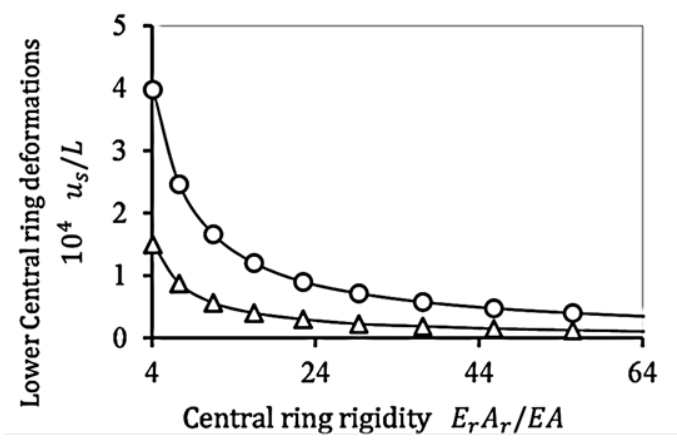

Fig. 28. Variation of lower central ring deformations with central rings stiffness and diameters ratio.

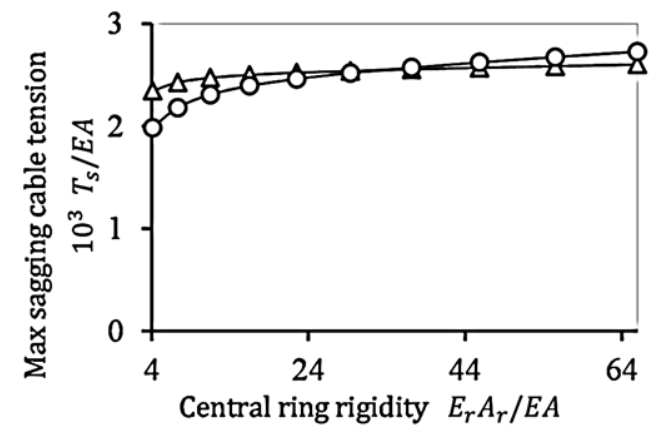

Fig. 29. Variation of sagging cable tensions with central rings stiffness and diameters ratio.

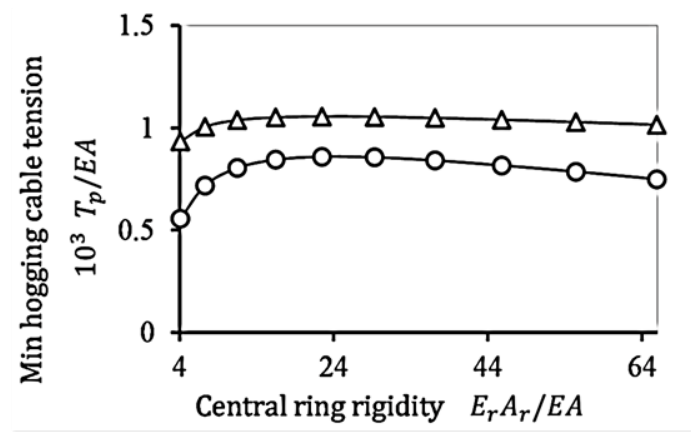

Fig. 30. Variation of hogging cable tensions with central rings stiffness and diameters ratio.

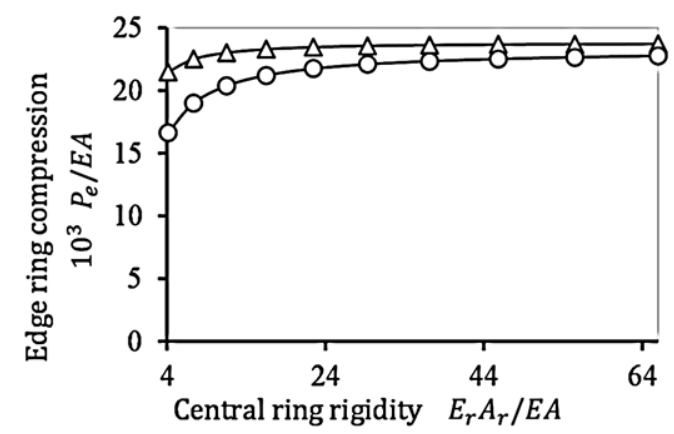

Fig. 31. Variation of edge ring compression forces with central rings stiffness and diameters ratio.

\section{E. Effect of the stiffness of the boundary structure on the response}

Figs. 32 to 38 , show results due to the variation of edge ring stiffness, $E_{e} A_{e}=2295$ to $36720 \mathrm{MN}$ for three values of load intensities $q=500,650$, and $900 \mathrm{~N} / \mathrm{m}^{2}$.While in Figs. 39 to 45 , the effects of column stiffness $E_{c} A_{c}=10000$ to $68340 \mathrm{MN}$ on the response are presented for three values of edge ring stiffness $E_{e} A_{e}=2295,6699$, and $36720 \mathrm{MN}$. The main features of the results are as follows:

1. The edge ring responses in a nonlinear manner due to the nonlinear behavior of the cables, which in turn greatly affects the response of the columns especially in case of low stiffness values of the edge beam.

2. The stiffness of a cable beam decreases with increasing flexibility and movements of the supporting system. When the supporting boundary is less stiff, as in case of cable ends not fixed but attached to elastic and deformable edge rings, the expected deflections are larger 
and the corresponding cable tensions are smaller.

3. Therefore, as the stiffness of the edge ring increases, the resultant deformations of the net are decreased. At the same time, each of the maximum tension in cables, the tension force of central rings, the compression force of the edge ring, and the maximum bending moments of the of columns are decreased.

4. Column stiffness does not significantly influence the net response, but slightly affects the internal forces of the edge ring.

With the following figures, Figs. 32 to 38 , the following symbols are considered to define the load intensity applied as:

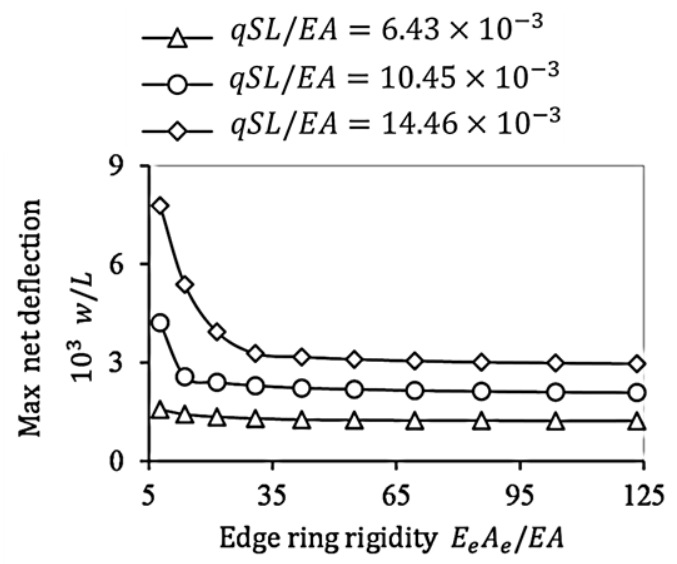

Fig. 32. Variation of net deflections with edge ring stiffness and load intensity.

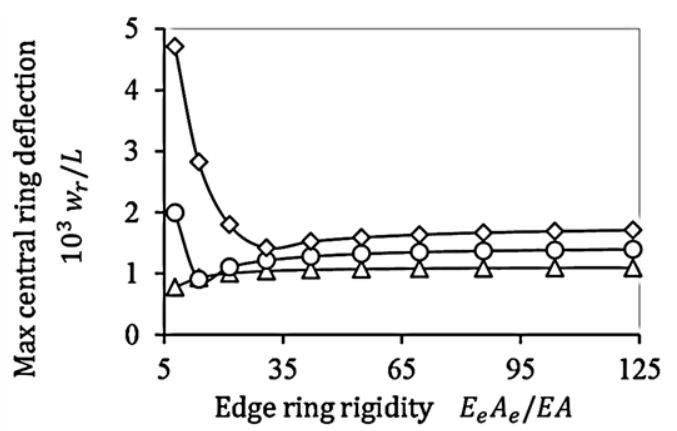

Fig. 33. Variation of central ring deflections with edge ring stiffness and load intensity.

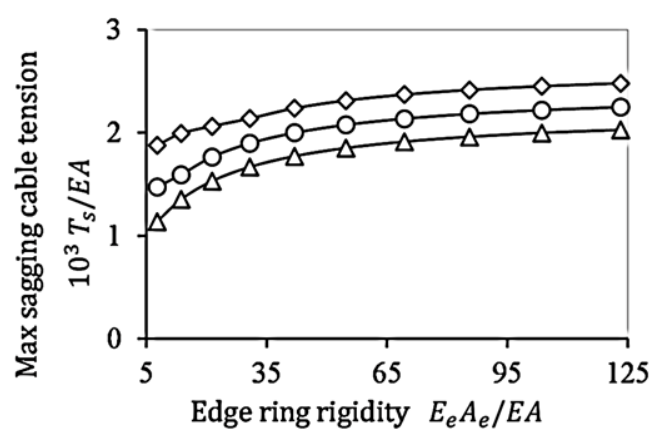

Fig. 34. Variation of sagging cable tensions with edge ring stiffness and load intensity.

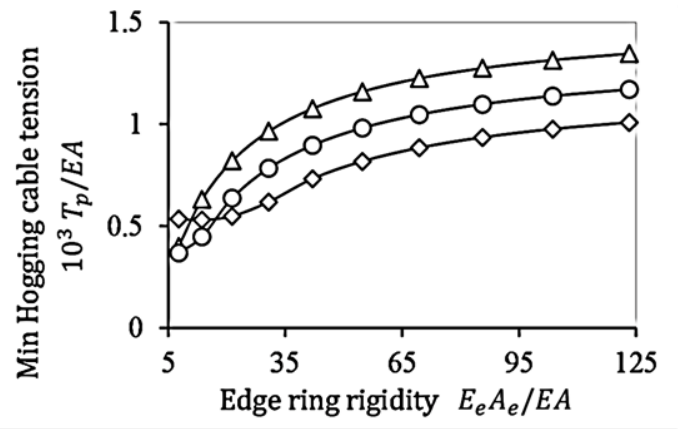

Fig. 35. Variation of hogging cable tensions with edge ring stiffness and load intensity.

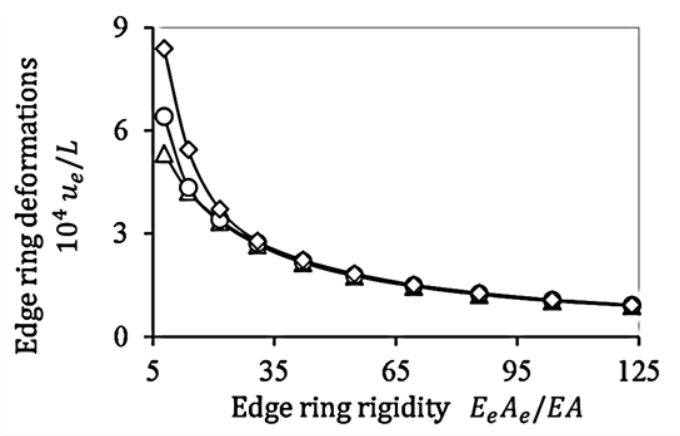

Fig. 36. Variation of edge ring deformations with edge ring stiffness and load intensity.

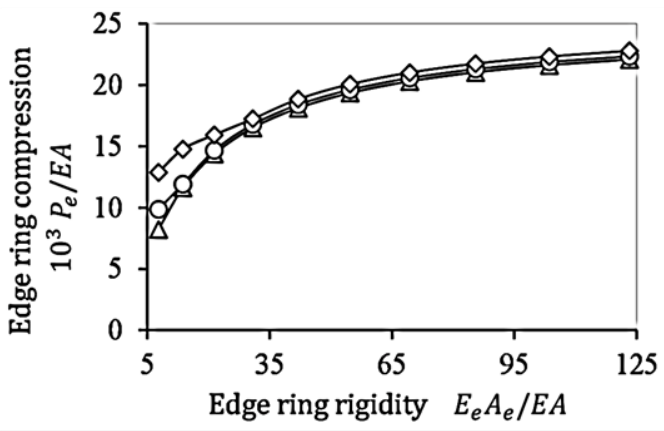

Fig. 37. Variation of edge ring compression forces with edge ring stiffness and load intensity.

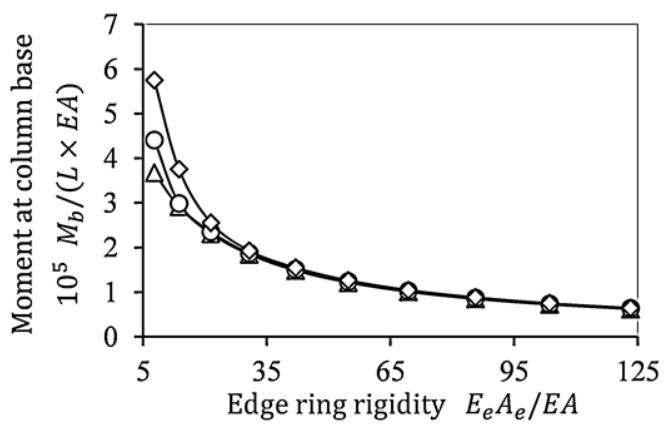

Fig. 38. Variation of moments at column base with edge ring stiffness and load intensity. 
With the following figures, Figs. 39 to 45 , the following symbols are used to indicate the utilized stiffness of the edge ring:

$$
\begin{aligned}
& \neg-q S L / E_{e} A_{e}=6.74 \times 10^{-5} \\
& \multimap-q S L / E_{e} A_{e}=1.69 \times 10^{-5} \\
& \multimap-q S L / E_{e} A_{e}=8.62 \times 10^{-6}
\end{aligned}
$$

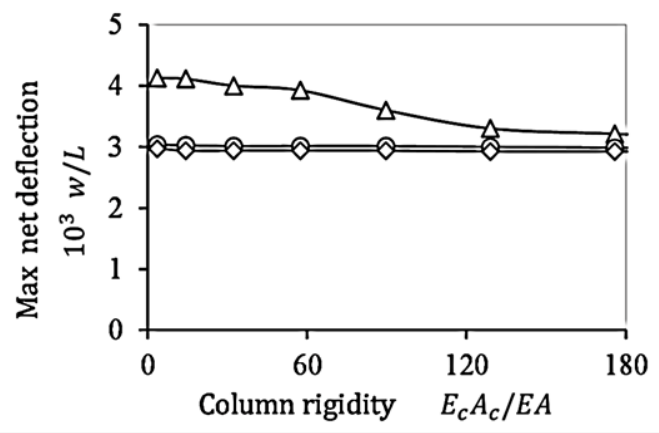

Fig. 39. Variation of net deflections with columns stiffness

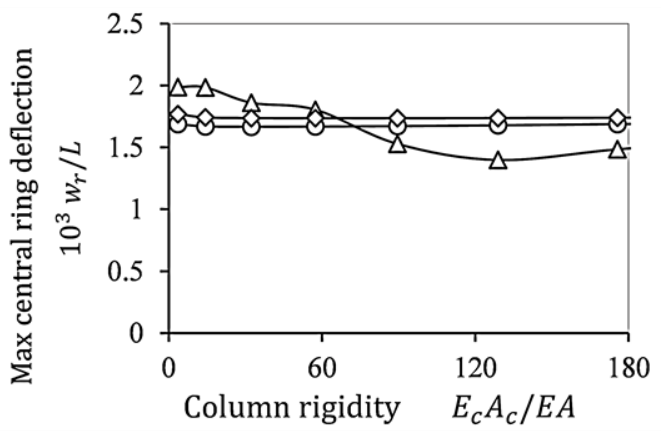

Fig. 40. Variation of central ring deflections with columns stiffness

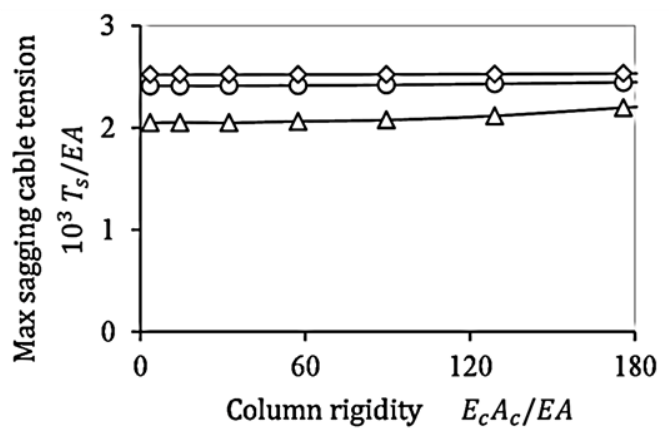

Fig. 41. Variation of sagging cable tensions with columns stiffness

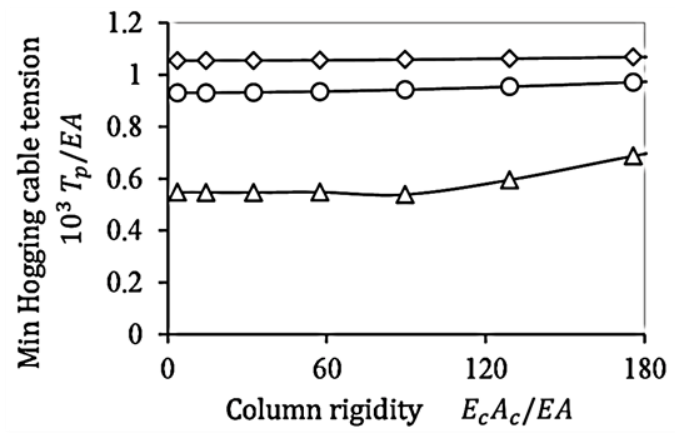

Fig. 42. Variation of hogging cable tensions with columns stiffness

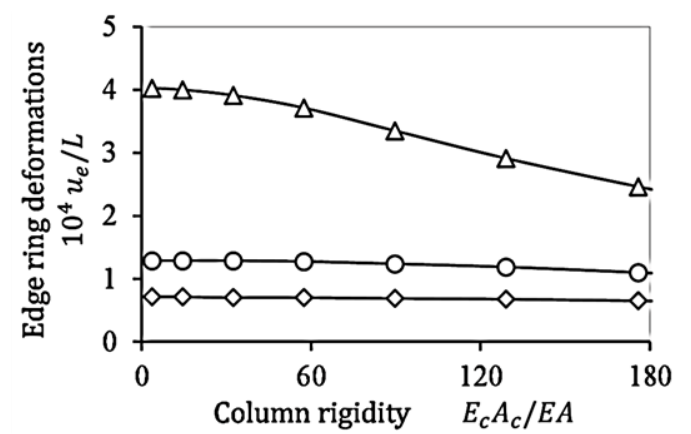

Fig. 43. Variation of edge ring deformations with columns stiffness

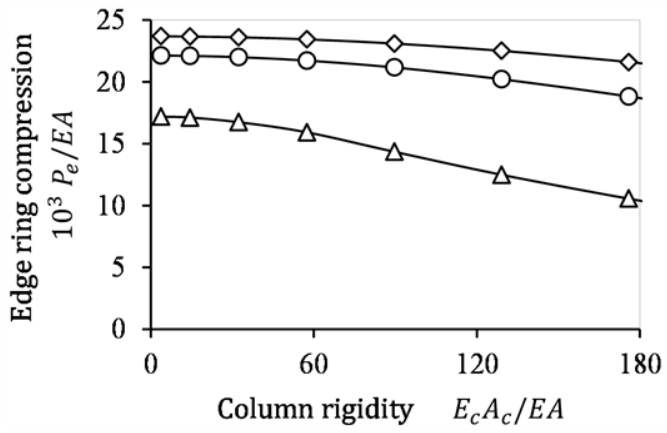

Fig. 44. Variation of edge ring compression forces with columns stiffness

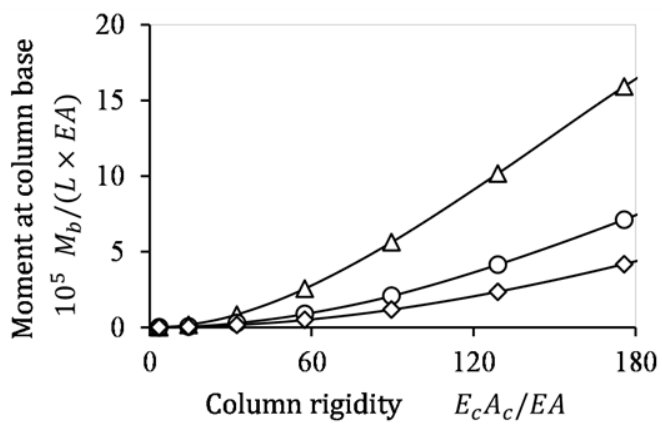

Fig. 45. Variation of moments at column base with columns stiffness

\section{TRANSFORMATION RELATIONSHIPS}

A well-known procedure used for preliminary design of suspension cable roofs has been presented by [20]. This method provides nondimensional graphs and tables constructed using a computer program based on the energy minimization approach. It can be used to obtain the nondimensional quantities for deflections, cable tensions and natural frequencies for several types of cable beams with rigid supports and subjected to uniformly distributed loads. The method suggested that:

1. Two systems have similar characteristics if: (i) the ratio of applying load to the cables extensional rigidity $(q S l / E A)$ is constant, (ii) the sag/ rise to span ratios $\left(f_{s} / L\right)$ and $\left(f_{p} / L\right)$ are constant, and (iii) the ratio of pretension force to the 
cables extensional rigidity $(H / E A)$ is constant. Consequently their corresponding response is expected to be identical. Thus. (iv) The maximum deflection to span ratio $(w / L)$ is constant, and $(\mathrm{v})$ the ratio of maximum tension to the cables extensional rigidity $\left(T_{s} / E A\right)$ is constant.

2. The preliminary design of the rings can be carried out by assuming that their normal forces are principally functions of the forces established by the horizontal components of the cable tensions. Therefore: (i) the tension of the upper central ring is directly proportional to the tension forces of the hogging $\operatorname{cables}\left(P_{p} \propto T_{p}\right)$, (ii) the tension of the lower central ring is directly proportional to the tension forces of the sagging cables $\left(P_{S} \propto T_{S}\right)$, and (iii) the tension of the edge ring is directly proportional to the tension forces of both the hogging and sagging cables $\left(P_{e} \propto T_{p}+T_{s}\right)$.

According to these assumptions and in the progression of our work to achieve transformation relationships to account for the edge ring flexibility and the cables curvature. It is supposed that:

1. Since columns of radial cable networks only marginally affect their stiffness. In order to reduce the computational effort, each of, the $z$ - displacements of the joints of the edge beam, the $x$-displacements for the two joints of the edge beam lie on the $x$-axis, and the y-displacements for the two joints of the edge beam lie on the $y$-axis were assumed to be restrained, so that the rigid body motion is prevented.

2. The proposed relationships are regarding the main characteristics that significantly influence the response of the network; and can be summarized in: (i) the extensional rigidity of the cables, where $\left(E_{s} A_{s}=E_{p} A_{p}=\right.$ $E A)$, (ii) the cables curvature, where $\left(f_{s} / L=f_{p} / L=f / L\right)$, (iii) the pretension force of the cables, where $\left(H_{s}=H_{p}=\right.$ $H$ ), (iv) the axial stiffness of the edge ring, (v)the maximum positive deflection of the net, (vi) the maximum and minimum tensions of the sagging and hogging cables (vii) the tensions forces of the upper and lower central rings, and (viii) maximum radial deformations and compression force of the edge ring.

The transformation relationships suggested for scaling of the prototype to the model with elastically deformable edge ring are presented. In the following $m$ and $t$ are subscripts point to the model and the prototype, respectively.

$$
\left(\frac{q S L}{E A}\right)_{m}=\left(\frac{q S L}{E A}\right)_{t}\left(\frac{f_{m} / L_{m}}{f_{t} / L_{t}}\right)^{2}
$$

Maximum applied load to cable extensional rigidity ratio.

$\left(\frac{H}{E A}\right)_{m}=\left(\frac{H}{E A}\right)_{t}\left(\frac{f_{m} / L_{m}}{f_{t} / L_{t}}\right)^{2}$

Pretension force to cable extensional rigidity ratio.

$$
\left(\frac{E_{e} A_{e}}{E A}\right)_{m}=\left(\frac{E_{e} A_{e}}{E A}\right)_{t}\left(\frac{f_{m} / L_{m}}{f_{t} / L_{t}}\right)^{2}\left(\frac{N_{m}}{N_{t}}\right)
$$

Edge ring extensional rigidity to cable extensional rigidity ratio.

$$
\left(\frac{E_{r} A_{r}}{E A}\right)_{m}=\left(\frac{E_{r} A_{r}}{E A}\right)_{t}\left(\frac{f_{m} / L_{m}}{f_{t} / L_{t}}\right)^{2}\left(\frac{N_{m}}{N_{t}}\right)
$$

Central ring extensional rigidity to cable extensional rigidity ratio.

$\left(\frac{w}{L}\right)_{m}=\left(\frac{w}{L}\right)_{t}$

Maximum net deflection to span ratio.

$\left(\frac{u_{e}}{L}\right)_{m}=\left(\frac{u_{e}}{L}\right)_{t}$

Maximum edge ring radial deformations to span ratio.

$\left(\frac{T_{s}}{E A}\right)_{m}=\left(\frac{T_{s}}{E A}\right)_{t}\left(\frac{f_{m} / L_{m}}{f_{t} / L_{t}}\right)^{2}$

Maximum sagging cables tension to cable extensional rigidity ratio.

$\left(\frac{T_{p}}{E A}\right)_{m}=\left(\frac{T_{p}}{E A}\right)_{t}\left(\frac{f_{m} / L_{m}}{f_{t} / L_{t}}\right)^{2.55}$

Minimum hogging cables tension to cable extensional rigidity ratio.

$\left(\frac{P_{p}}{E A}\right)_{m}=\left(\frac{P_{p}}{E A}\right)_{t}\left(\frac{f_{m} / L_{m}}{f_{t} / L_{t}}\right)^{2.55}\left(\frac{N_{m}}{N_{t}}\right)$

Maximum upper central ring tension to cable extensional rigidity ratio.

$\left(\frac{P_{s}}{E A}\right)_{m}=\left(\frac{P_{s}}{E A}\right)_{t}\left(\frac{f_{m} / L_{m}}{f_{t} / L_{t}}\right)^{2}\left(\frac{N_{m}}{N_{t}}\right)$

Maximum lower central ring tension to cable extensional rigidity ratio.

$\left(\frac{P_{e}}{E A}\right)_{m}=\left(\frac{P_{e}}{E A}\right)_{t}\left(\frac{f_{m} / L_{m}}{f_{t} / L_{t}}\right)^{2}\left(\frac{N_{m}}{N_{t}}\right)$

Maximum edge ring compression to cable extensional rigidity ratio.

In order to verify the accuracy of the transformation relationships, several models are analyzed with different values of number of cable beams and sag/rise to span ratios. The analysis is carried out with keeping other parameters unchanged in both prototype and model. Table 3 shows the results from different analyses, based on a prototype of 42 cables, and several models with 10 to 80 cables with step of 10 cables.

The results obtained for the maximum tensions and deflections show that the model and the prototype are in excellent agreement. Also, Table 4 shows the results for a prototype with a sag/rise to span ratio of $4 \%$ and models with ratios between $4.5 \%$ and $6 \%$ with step $0.5 \%$. In this case, the resulting error for maximum tensions was within $-8 \%$ and $-3 \%$ 
while that for deflections was within $-2 \%$ and $-1 \%$.

TABLE 3

CONVEX CABLE BEAMS, (SAG=RISE): MAXIMUM TENSIONS AND NET DEFLECTIONS FOR DIFFERENT NUMBER OF CABLE BEAMS $q S L / E A=2.15 \times 10^{-3}$

\begin{tabular}{l||c||c||c}
\hline & $\begin{array}{c}\text { Number of } \\
\text { cable beams } \\
\boldsymbol{N}\end{array}$ & $\begin{array}{c}\text { Net deflection } \\
\mathbf{1 0}^{\mathbf{3}} \boldsymbol{w} \mathbf{L}\end{array}$ & $\begin{array}{c}\text { Max cable } \\
\text { tension } \\
\mathbf{1 0}^{\mathbf{3}} \boldsymbol{T} \mathbf{s} \boldsymbol{E} \boldsymbol{A}\end{array}$ \\
\hline Prototype & $\mathbf{4 2}$ & $\mathbf{4 . 3 2 5 0}$ & $\mathbf{3 . 1 6 8 6}$ \\
\hline Model & 10 & 4.3375 & 3.1679 \\
\hline Model & 20 & 4.3250 & 3.1701 \\
\hline Model & 30 & 4.3250 & 3.1691 \\
\hline Model & 40 & 4.3250 & 3.1687 \\
\hline Model & 50 & 4.3250 & 3.1684 \\
\hline Model & 60 & 4.3250 & 3.1689 \\
\hline Model & 70 & 4.3250 & 3.1683 \\
\hline Model & 80 & 4.3250 & 3.1684 \\
\hline
\end{tabular}

TABLE 4

CONVEX CABLE BEAMS, (SAG=RISE): MAXIMUM TENSIONS AND NET DEFLECTIONS FOR DIFFERENT CABLES CURVATURE $q S L E A=2.0 \times 10^{-3}$

\begin{tabular}{l||c||c||c}
\hline & $\begin{array}{c}\text { Sag/Rise } \\
f / L\end{array}$ & $\begin{array}{c}\text { Net deflection } \\
\mathbf{1 0}^{3} w / L\end{array}$ & $\begin{array}{c}\text { Max cable } \\
\text { tension } \\
\mathbf{1 0}^{3} \boldsymbol{T} / \boldsymbol{E A}\end{array}$ \\
\hline Prototype & $\mathbf{4 \%}$ & $\mathbf{4 . 1 6 2 5}$ & $\mathbf{2 . 9 6 8 3}$ \\
\hline Model & $\mathbf{4 . 5 \%}$ & 4.1375 & 2.8895 \\
\hline Model & $\mathbf{5 \%}$ & 4.1125 & 2.8276 \\
\hline Model & $\mathbf{5 . 5 \%}$ & 4.1125 & 2.7778 \\
\hline Model & $\mathbf{6 \%}$ & 4.1000 & 2.7370 \\
\hline
\end{tabular}

\section{PRELIMINARY ANALYSIS GRAPHS AND ILLUSTRATIVE EXAMPLES}

The $80 \mathrm{~m}$ model previously illustrated in section II again is analyzed for the construction of the graphs. In this analysis, sizes and pretension forces for both the sagging and the hogging cables are kept equal. All cable sizes are assumed according to ASTM: A586 - 04a standards [21], with nominal diameters ranged from $30 \mathrm{~mm}$ to $63.5 \mathrm{~mm}$ in order to have a range of cable extensional rigidity from 100 to $400 \mathrm{MN}$.

The supposed load intensities and the pretension are taken as percentage of the cable extensional rigidity. The study is carried out for a wide range of load intensities, $q S L / E A=$ $0.25 \times 10^{-3}$ to $5 \times 10^{-3}$, and pretension forces, $H / E A=1 \times 10^{-3}$ to
$5 \times 10^{-3}$.

Graphs achieved are dimensionless and can be applied for all systems of units. They provide the maximum and minimum tensions, maximum positive deflections of the net, and maximum normal forces and deformations of rings (Figs. 46 to 49) for $E_{e} A_{e} / E A=125$ to 500. Also, values of the same nondimensional parameters mentioned above are tabulated in Tables 9 to 12 .

When the preliminary graphs were constructed, the outcomes of the response in the state in which the final tensions in part of hogging cables are approaching to zero were eliminated. In order to provide accurate and precise results. Whereas, the loss of the tensile strength in the cables causes the net to be unstable. This occurs significantly when the load is greater than the pretension force.

\section{A. ILLUSTRATIVE EXAMPLE (1)}

In order to demonstrate the use of the non-dimensional diagrams and tables given in this paper, the preliminary design calculations for a $100 \mathrm{~m}$ diameter circular cable roof with radial convex cable beams with design parameters given as shown under the first column of Table 5.

TABLE 5

PROPERTIES OF CABLES UTILIZED IN THE PARAMETRIC STUDY

\begin{tabular}{l||c||c}
\hline \multicolumn{1}{c||}{ Parameters } & Example (1) & Example (2) \\
\hline Net diameter, $L(\mathrm{~m})$ & 100 & 60 \\
\hline Sag=Rise, $f / L(\%)$ & $4 \%$ & $5 \%$ \\
\hline Load intensity, $q\left(\mathrm{KN} / \mathrm{m}^{2}\right)$ & 1.0 & 1.15 \\
\hline Number of cable beams, $N$ & 56 & 56.23 \\
\hline $\begin{array}{l}\text { Spacing between cable } \\
\text { beams, } \mathrm{S}(\mathrm{m})\end{array}$ & 5.61 & 155 \\
\hline $\begin{array}{l}\text { Cables extensional rigidity, } \\
\text { EA }(\mathrm{MN})\end{array}$ & 300 & 387.5 \\
\hline \begin{tabular}{l} 
Pretension force, $H(\mathrm{KN})$ \\
\hline $\begin{array}{l}\text { Edge ring extensional } \\
\text { rigidity, } E e A \text { e }(\mathrm{MN})\end{array}$
\end{tabular} & 600 & 35000 \\
\hline
\end{tabular}

These prototype characteristics can be used to yield the nondimensional parameters of the model, for which the preliminary charts have been produced using equations (1 to 3). Hence:

$$
\begin{aligned}
& \left(\frac{q S L}{E A}\right)_{m}=\left(\frac{1.0 \times 5.61 \times 100}{300000}\right) \times\left(\frac{4}{4}\right)^{2}=1.87 \times 10^{-3} ; \\
& \left(\frac{H}{E A}\right)_{m}=\frac{600}{300000} \times\left(\frac{4}{4}\right)^{2}=2 \times 10^{-3} ; \text { and } \\
& \left(\frac{E_{e} A_{e}}{E A}\right)_{m}=\frac{50000}{300} \times\left(\frac{4}{4}\right)^{2} \times\left(\frac{42}{56}\right)=125
\end{aligned}
$$


Using preliminary curves of Fig. 46 for $E_{e} A_{e} / E A=125$, the curve for $q S L / E A=1.87 \times 10^{-3}$ can be plotted by interpolating the values of $1.5 \times 10^{-3}$ and $2.0 \times 10^{-3}$. Using the resulting curves, the model responses can be derived as recorded under the first column of Table 6 .

These values can be scaled back to the prototype using equations (5 to 11) as given below:

$$
\begin{aligned}
& w=4.05 \times 10^{-3} \times 100=405 \mathrm{~mm} ; \\
& u_{e}=1 \times 10^{-4} \times 100=10 \mathrm{~mm} ; \\
& T_{s}=2.80 \times 10^{-3} \times 300000=840 \mathrm{KN} ; \\
& T_{p}=0.96 \times 10^{-3} \times 300000=288 \mathrm{KN} ; \\
& P_{p}=6.40 \times 10^{-3} \times 300000 \times\left(\frac{56}{42}\right)=2560 \mathrm{KN} ; \\
& P_{s}=18.46 \times 10^{-3} \times 300000 \times\left(\frac{56}{42}\right)=7384 K N ; \text { and } \\
& P_{e}=24.56 \times 10^{-3} \times 300000 \times\left(\frac{56}{42}\right)=9824 K N
\end{aligned}
$$

TABLE 6

NONDIMENSIONAL PRELIMINARY RESPONSE OF THE MODELS USED IN THE ILLUSTRATIVE EXAMPLES

\begin{tabular}{c||c||c}
\hline Response & Example (1) & Example (2) \\
\hline \multicolumn{1}{c||}{$(\mathrm{L})$} & $1.05 \times 10^{-3}$ & $3.50 \times 10^{-3}$ \\
\hline ue/L & $2.80 \times 10^{-3}$ & $6.00 \times 10^{-4}$ \\
\hline$T s / E A$ & $0.96 \times 10^{-3}$ & $2.31 \times 10^{-3}$ \\
\hline$T p / E A$ & $6.40 \times 10^{-3}$ & $0.79 \times 10^{-3}$ \\
\hline$P p / E A$ & $18.46 \times 10^{-3}$ & $5.27 \times 10^{-3}$ \\
\hline$P s / E A$ & $24.60 \times 10^{-3}$ & $15.26 \times 10^{-3}$ \\
\hline$P e / E A$ & & $20.30 \times 10^{-3}$ \\
\hline
\end{tabular}

In order to comprehend the proposed method, a nonlinear analysis of the prototype is carried out. Table. 7 shows that the results obtained from the proposed method are in great agreement with that obtained using SAP2000. Where, the accuracy is almost $97 \%$ for the net deflections, $99 \%$ for the cable maximum tensions, $92 \%$ for the cable minimum tensions, $92 \%$ and $99 \%$ for the upper and lower central rings tension forces respectively, and $98 \%$ for the edge ring compression force.
TABLE 7

RESULTS OF THE ANALYSIS OF THE PROTOTYPE USED IN ILLUSTRATIVE EXAMPLE (1)

\begin{tabular}{l||c||c||c}
\hline \multicolumn{1}{c||}{ Response } & Present study & SAP2000 & $\begin{array}{c}\text { Minimization } \\
\text { of T.P.E }\end{array}$ \\
\hline $\begin{array}{l}\text { Max deflection, } w \\
(\mathrm{~mm})\end{array}$ & 405 & 393 & 394 \\
\hline $\begin{array}{l}\text { Max sagging } \\
\text { tension, } T s(\mathrm{KN})\end{array}$ & 840 & 849 & 848 \\
\hline $\begin{array}{l}\text { Min hogging } \\
\text { tension, } T p(\mathrm{KN})\end{array}$ & 288 & 267 & 268 \\
\hline $\begin{array}{l}\text { Upper central } \\
\text { ring tension, } P p \\
(\mathrm{KN})\end{array}$ & 2560 & 2381 & 2386 \\
\hline $\begin{array}{l}\text { Lower central } \\
\text { ring tension, } P s \\
(\mathrm{KN})\end{array}$ & 7384 & 7444 & 7456 \\
\hline $\begin{array}{l}\text { Edge ring } \\
\text { compression, } \\
P e(\mathrm{KN})\end{array}$ & 9842 & 9641 & 9655 \\
\hline
\end{tabular}

\section{B. ILLUSTRATIVE EXAMPLE (2)}

For the second case of study the prototype has a different curvature from the model with the characteristics presented under the second column of Table 5. The prototype parameters can be scaled to the model for which the preliminary charts have been produced by setting:

$$
\begin{aligned}
& \left(\frac{q S L}{E A}\right)_{m}=\left(\frac{1.15 \times 5.23 \times 60}{155000}\right) \times\left(\frac{4}{5}\right)^{2}=1.50 \times 10^{-3} \\
& \left(\frac{H}{E A}\right)_{m}=\frac{387.5}{155000} \times\left(\frac{4}{5}\right)^{2}=1.6 \times 10^{-3} \\
& \left(\frac{E_{e} A_{e}}{E A}\right)_{m}=\frac{31250}{155} \times\left(\frac{4}{5}\right)^{2} \times\left(\frac{42}{36}\right)=168
\end{aligned}
$$

Using preliminary curves of Fig. 47 for EeAe/EA $=167$, the model response can be determined as shown under the second column of Table 6 . These values can be scaled back to the prototype using equations (5 to 11 ) similarly as in the previous example. Hence:

$$
\begin{aligned}
& w=3.50 \times 10^{-3} \times 60=210 \mathrm{~mm} ; \\
& u_{e}=6 \times 10^{-4} \times 60=3.6 \mathrm{~mm} ; \\
& T_{s}=2.31 \times 10^{-3} \times 155000 \times\left(\frac{5}{4}\right)^{2}=559.45 \mathrm{KN} ; \\
& T_{p}=0.79 \times 10^{-3} \times 155000 \times\left(\frac{5}{4}\right)^{2.55}=216.31 \mathrm{KN} ; \\
& P_{p}=5.27 \times 10^{-3} \times 155000 \times\left(\frac{36}{42}\right) \times\left(\frac{5}{4}\right)^{2.55}=1236.85 \mathrm{KN} ; \\
& P_{s}=15.26 \times 10^{-3} \times 155000 \times\left(\frac{36}{42}\right) \times\left(\frac{5}{4}\right)^{2}=3167.81 \mathrm{KN} ; \text { and } \\
& P_{e}=20.30 \times 10^{-3} \times 155000 \times\left(\frac{36}{42}\right) \times\left(\frac{5}{4}\right)^{2}=4214.06 \mathrm{KN}
\end{aligned}
$$

Results due to nonlinear analyses and the preliminary method are given in Table 8. It is noted that, the accuracy is approximately $97 \%$ for the net deflections, $95 \%$ for the cable maximum tensions, $96 \%$ for the cable minimum tensions, $97 \%$ and $94 \%$ for the upper and lower central rings tension forces respectively, and $99 \%$ for the edge ring compression force. 
TABLE 8

RESULTS OF THE ANALYSIS OF THE PROTOTYPE USED IN ILLUSTRATIVE EXAMPLE (2)

\begin{tabular}{l||c||c||c}
\hline \multicolumn{1}{c||}{ Response } & Present study & SAP2000 & Minimization of T.P.E \\
\hline Max deflection, $w(\mathrm{~mm})$ & 210 & 204 & 205 \\
\hline Max sagging tension, $T s(\mathrm{KN})$ & 559.45 & 533 & 525 \\
\hline Min hogging tension, $T p(\mathrm{KN})$ & 216.31 & 224 & 216 \\
\hline Upper central ring tension, $P p(\mathrm{KN})$ & 1236.85 & 1280 & 1238 \\
\hline Lower central ring tension, $P s(\mathrm{KN})$ & 3167.81 & 2984 & 2953 \\
\hline Edge ring compression, $P e(\mathrm{KN})$ & 4214.06 & 4246 & 4143 \\
\hline
\end{tabular}

TABLE 9

THE PRELIMINARY RESPONSE OF THE CONVEX CABLE BEAMS ROOF FOR SAG/RISE TO SPAN RATIO $f=4 \% L$, LOAD INTENSITY $q S L E A=1.0 \times 10^{-3}$ to $3.0 \times 10^{-3}$, PRETENSION FORCE $H / E A=1 \times 10^{-3}$ to $5 \times 10^{-3}$, EDGE RING RIGIDITY Ee $A e / E A=125$. Triangular distributed load, $\quad$ SSLEA $=1 \times 10^{-3}$

\begin{tabular}{|c|c|c|c|c|c|c|}
\hline $10^{3} H / E A$ & $10^{3} w / L$ & $10^{3} T_{S} / E A$ & $10^{3} T p / E A$ & $10^{3} P p / E A$ & $10^{3} P S / E A$ & $10^{3} \mathrm{Pe} / \mathrm{EA}$ \\
\hline 1 & 2.9875 & 1.5185 & 0.4437 & 2.9828 & 10.0222 & 12.8498 \\
\hline 2 & 2.2125 & 2.2828 & 1.2827 & 8.5789 & 15.0837 & 23.3829 \\
\hline 3 & 1.8625 & 3.1040 & 2.1681 & 14.4941 & 20.5164 & 34.5949 \\
\hline 4 & 1.6750 & 3.9403 & 3.0578 & 20.4383 & 26.0403 & 45.9347 \\
\hline 5 & 1.5625 & 4.7839 & 3.9473 & 26.3862 & 31.6174 & 57.3170 \\
\hline
\end{tabular}

Triangular distributed load, $\quad q S L / E A=2 \times 10^{-3}$

\begin{tabular}{l||l||c||c||c||c||c||}
\hline 2 & 4.3125 & 2.8765 & 1.0916 & 6.1076 & 18.9866 & 24.7880 \\
\hline 3 & 3.6750 & 3.6235 & 1.6157 & 11.9488 & 23.9226 & 35.4591 \\
\hline 4 & 3.2875 & 4.4108 & 2.5179 & 17.9713 & 29.1207 & 46.5415 \\
\hline 5 & 3.0500 & 5.2177 & 3.4278 & 24.0136 & 34.4569 & 57.7812 \\
\hline
\end{tabular}

Triangular distributed load, $q S L / E A=3 \times 10^{-3}$

\begin{tabular}{l||c||c||c||c||c||c}
\hline 3 & 5.4125 & 4.1713 & 1.4545 & 9.7128 & 27.5277 & 36.7969 \\
\hline 4 & 4.8750 & 4.9044 & 2.3545 & 15.7355 & 32.3587 & 47.5285 \\
\hline 5 & 4.5375 & 5.6697 & 3.2692 & 21.8354 & 37.4094 & 58.5515 \\
\hline
\end{tabular}

TABLE 10

THE PRELIMINARY RESPONSE OF THE CONVEX CABLE BEAMS ROOF FOR SAG/RISE TO SPAN RATIO $f=4 \% L$, LOAD INTENSITY $q S L E A=1.0 \times 10^{-3}$ to $3.0 \times 10^{-3}$, PRETENSION FORCE $H / E A=1 \times 10^{-3}$ to $5 \times 10^{-3}$, EDGE RING RIGIDITY Ee $A e / E A=167$. Triangular distributed load, $\quad q S L / E A=1 \times 10^{-3}$

\begin{tabular}{|c|c|c|c|c|c|c|}
\hline $10^{3} H / E A$ & $10^{3} w / L$ & $10^{3} T s / E A$ & $10^{3} T p / E A$ & $10^{3} P p / E A$ & $10^{3} P_{S} / E A$ & $10^{3} \mathrm{Pe} / \mathrm{EA}$ \\
\hline 1 & 2.9125 & 1.5437 & 0.4733 & 3.1695 & 10.1942 & 13.2012 \\
\hline 2 & 2.1625 & 2.3395 & 1.3434 & 8.9820 & 15.4614 & 24.1555 \\
\hline 3 & 1.8250 & 3.1903 & 2.2584 & 15.1031 & 21.0903 & 35.7611 \\
\hline 4 & 1.6250 & 4.0560 & 3.1785 & 21.2497 & 26.8032 & 47.4900 \\
\hline 5 & 1.5125 & 4.9289 & 4.0973 & 27.3846 & 32.5769 & 59.2598 \\
\hline
\end{tabular}

Triangular distributed load,$\quad q S L / E A=2 \times 10^{-3}$

\begin{tabular}{l||l||c||c||c||c||c}
\hline 2 & 25.5412 & 2.9298 & 0.9734 & 6.5032 & 19.3391 & 25.5412 \\
\hline 3 & 36.6081 & 3.7063 & 1.8810 & 12.5718 & 24.4746 & 36.6081 \\
\hline 4 & 48.0967 & 4.5229 & 2.8120 & 18.7963 & 29.8679 & 48.0967 \\
\hline 5 & 59.7236 & 5.3582 & 3.7470 & 25.0416 & 35.3915 & 59.7236 \\
\hline
\end{tabular}

Triangular distributed load, $\quad$ qSLEA $=3 \times 10^{-3}$

\begin{tabular}{l||l||l||l||l||l||l}
\hline 3 & 5.2875 & 4.2509 & 1.5488 & 10.3489 & 28.0443 & 37.9453 \\
\hline 4 & 4.7625 & 5.0128 & 2.4805 & 16.5628 & 33.0846 & 49.0711 \\
\hline 5 & 4.4250 & 5.8075 & 3.4242 & 22.8758 & 38.3367 & 60.4835 \\
\hline
\end{tabular}


TABLE 11

THE PRELIMINARY RESPONSE OF THE CONVEX CABLE BEAMS ROOF FOR SAG/RISE TO SPAN RATIO $f=4 \% L$, LOAD INTENSITY $q S L E A=1.0 \times 10^{-3}$ to $3.0 \times 10^{-3}$, PRETENSION FORCE $H / E A=1 \times 10^{-3}$ to $5 \times 10^{-3}$, EDGE RING RIGIDITY Ee $A e / E A=250$.

Triangular distributed load, $\quad$ qSLEA $=1 \times 10^{-3}$

\begin{tabular}{c||c||c||c||c||c||c}
$\mathbf{1 0}^{3}$ H/EA & $\mathbf{1 0}^{3}$ w/L & $\mathbf{1 0}^{3} \boldsymbol{T} / \boldsymbol{E A}$ & $\mathbf{1 0}^{3} \boldsymbol{T} \boldsymbol{s} / \boldsymbol{E A}$ & $\mathbf{1 0}^{3} \boldsymbol{P p} / \mathbf{E A}$ & $\mathbf{1 0}^{\mathbf{3}} \boldsymbol{P S} / \boldsymbol{E A}$ & $\mathbf{1 0}^{3} \boldsymbol{P e} / \boldsymbol{E A}$ \\
\hline 1 & 2.8500 & 1.5727 & 0.5038 & 3.3702 & 10.3847 & 13.5940 \\
\hline 2 & 2.1125 & 2.4006 & 1.4079 & 9.4131 & 15.8643 & 24.9813 \\
\hline 3 & 1.7750 & 3.2827 & 2.3549 & 15.7522 & 21.7048 & 37.0088 \\
\hline 4 & 1.5875 & 4.1793 & 3.3069 & 22.1181 & 27.6280 & 49.1576 \\
\hline 5 & 1.4750 & 5.0838 & 4.2577 & 28.4653 & 33.6076 & 61.3434 \\
\hline
\end{tabular}

Triangular distributed load, $q S L / E A=2 \times 10^{-3}$

\begin{tabular}{l||l||l||l||l||l||l}
\hline 1 & 7.3625 & 2.6632 & 0.8666 & 5.9533 & 17.6898 & 23.1051 \\
\hline 2 & 4.1250 & 2.9869 & 1.0393 & 6.9434 & 19.7154 & 26.3497 \\
\hline 3 & 3.5000 & 3.7958 & 1.9801 & 13.2336 & 25.0651 & 37.8449 \\
\hline 4 & 3.1375 & 4.6436 & 2.9440 & 19.6744 & 30.6673 & 49.7521 \\
\hline 5 & 2.9000 & 5.5101 & 3.9115 & 26.1389 & 36.3961 & 61.8032 \\
\hline
\end{tabular}

Triangular distributed load, $q S L / E A=3 \times 10^{-3}$

\begin{tabular}{l||l||l||l||l||l||l}
\hline 3 & 5.1625 & 4.3361 & 1.6502 & 11.0219 & 28.6102 & 39.1744 \\
\hline 4 & 4.6625 & 5.1300 & 2.6146 & 17.4762 & 33.8659 & 50.7282 \\
\hline 5 & 4.3125 & 5.9554 & 3.5912 & 24.0043 & 39.3209 & 62.5730 \\
\hline
\end{tabular}

TABLE 12

THE PRELIMINARY RESPONSE OF THE CONVEX CABLE BEAMS ROOF FOR SAG/RISE TO SPAN RATIO $f=4 \% L$, LOAD INTENSITY $q S L / E A=1.0 \times 10^{-3}$ to $3.0 \times 10^{-3}$, PRETENSION FORCE $H / E A=1 \times 10^{-3}$ to $5 \times 10^{-3}$, EDGE RING RIGIDITY Ee $A e / E A=500$.

Triangular distributed load, $q S L E A=1 \times 10^{-3}$

\begin{tabular}{c||c||c||c||c||c||c}
$\mathbf{1 0}^{3} \mathrm{H} / \mathrm{EA}$ & $\mathbf{1 0}^{3}$ w/L & $\mathbf{1 0}^{3} \boldsymbol{T} / \boldsymbol{E A}$ & $\mathbf{1 0}^{3} \boldsymbol{T} \boldsymbol{p} / \boldsymbol{E A}$ & $\mathbf{1 0}^{3} \boldsymbol{P p} / \boldsymbol{E A}$ & $\mathbf{1 0}^{3} \boldsymbol{P S} / \boldsymbol{E A}$ & $\mathbf{1 0}^{3} \boldsymbol{P e} / \boldsymbol{E A}$ \\
\hline 1 & 2.7875 & 1.6037 & 0.5367 & 3.5938 & 10.5930 & 14.0125 \\
\hline 2 & 2.0625 & 2.4657 & 1.4772 & 9.8785 & 16.2954 & 25.8672 \\
\hline 3 & 1.7250 & 3.3815 & 2.4594 & 16.4430 & 22.3491 & 38.3445 \\
\hline 4 & 1.5375 & 4.3126 & 3.4452 & 23.0431 & 28.5156 & 50.9499 \\
\hline 5 & 1.4250 & 5.2500 & 4.4297 & 29.6209 & 34.7146 & 63.5798 \\
\hline
\end{tabular}

Triangular distributed load, $q S L E A=2 \times 10^{-3}$

\begin{tabular}{l||c||c||c||c||c||c}
\hline 1 & 7.0625 & 2.6838 & 0.8687 & 5.9635 & 17.8379 & 23.2456 \\
\hline 2 & 4.0250 & 3.0489 & 1.1094 & 7.4155 & 20.1289 & 27.2215 \\
\hline 3 & 3.4125 & 3.8910 & 2.0863 & 13.9506 & 25.7022 & 39.1747 \\
\hline 4 & 3.0625 & 4.7724 & 3.0851 & 20.6262 & 31.5383 & 51.5375 \\
\hline 5 & 2.8250 & 5.6726 & 4.0871 & 27.3253 & 37.4874 & 64.0394 \\
\hline
\end{tabular}

Triangular distributed load, $q S L E A=3 \times 10^{-3}$

\begin{tabular}{l||l||l||l||l||l||l||}
\hline 3 & 5.0375 & 4.4282 & 1.7582 & 11.7438 & 29.2251 & 40.4936 \\
\hline 4 & 4.5500 & 5.2557 & 2.7579 & 18.4282 & 34.6996 & 52.5045 \\
\hline 5 & 4.2125 & 6.1145 & 3.7697 & 25.1977 & 40.3830 & 64.8010 \\
\hline
\end{tabular}


The following symbols are used to indicate the pretention forces for Figs. 46 to 49:

$$
\begin{array}{ll}
\longrightarrow H / E A=1 \times 10^{-3} & \longrightarrow H / E A=2 \times 10^{-3} \\
\rightarrow H / E A=3 \times 10^{-3} & \longrightarrow-H / E A=4 \times 10^{-3} \\
\rightarrow H / E A=5 \times 10^{-3} &
\end{array}
$$
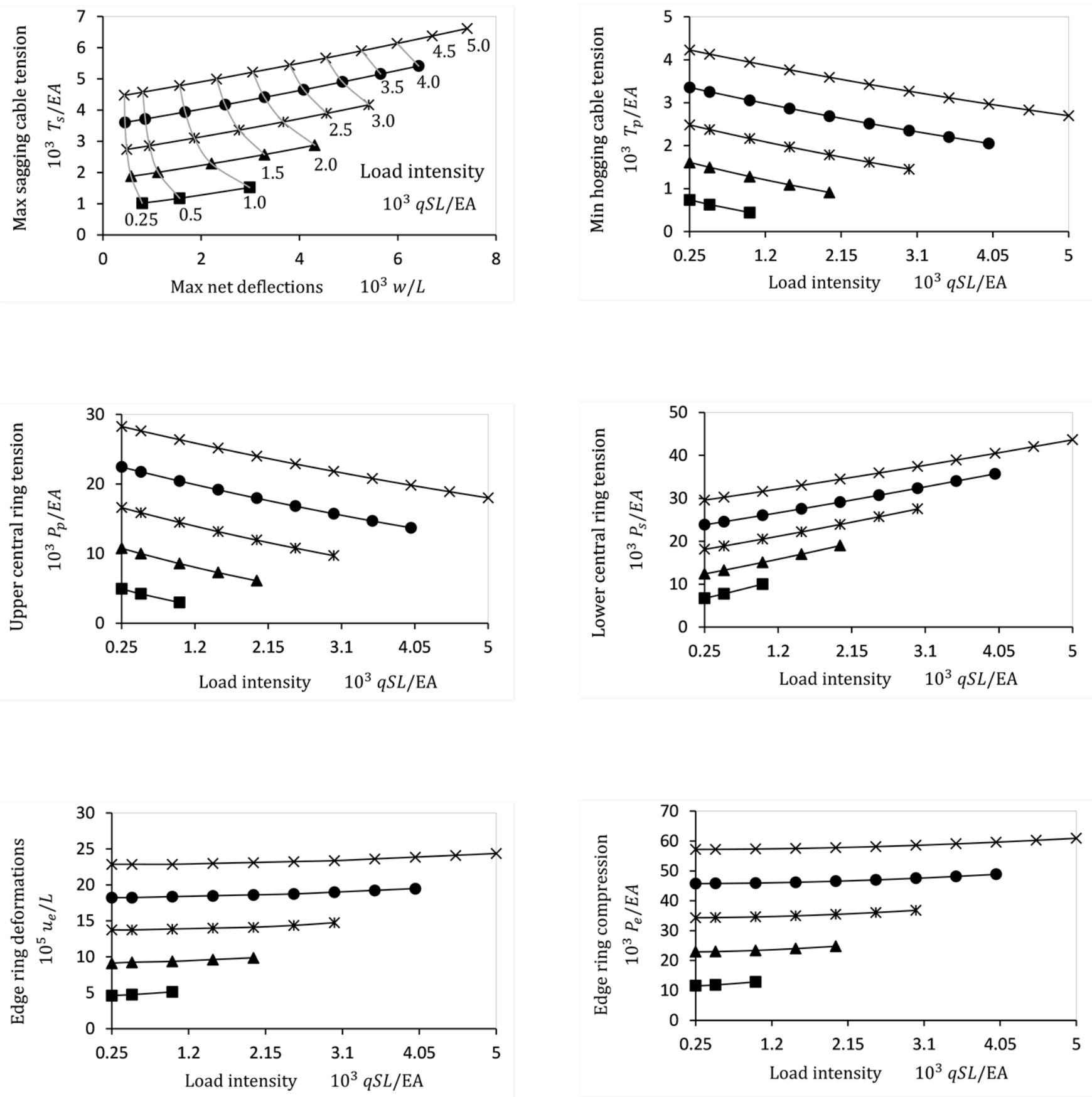

Fig. 46. Response of the convex cable roof beams, for sag/rise to span ratio $f=4 \% L$, load intensity $q S L E A=0.25 \times 10^{-3}$ to $5 \times 10^{-3}$, pretension force $H / E A=$ $1 \times 10^{-3}$ to $5 \times 10^{-3}$, and edge ring rigidity $E e A e / E A=125$. 

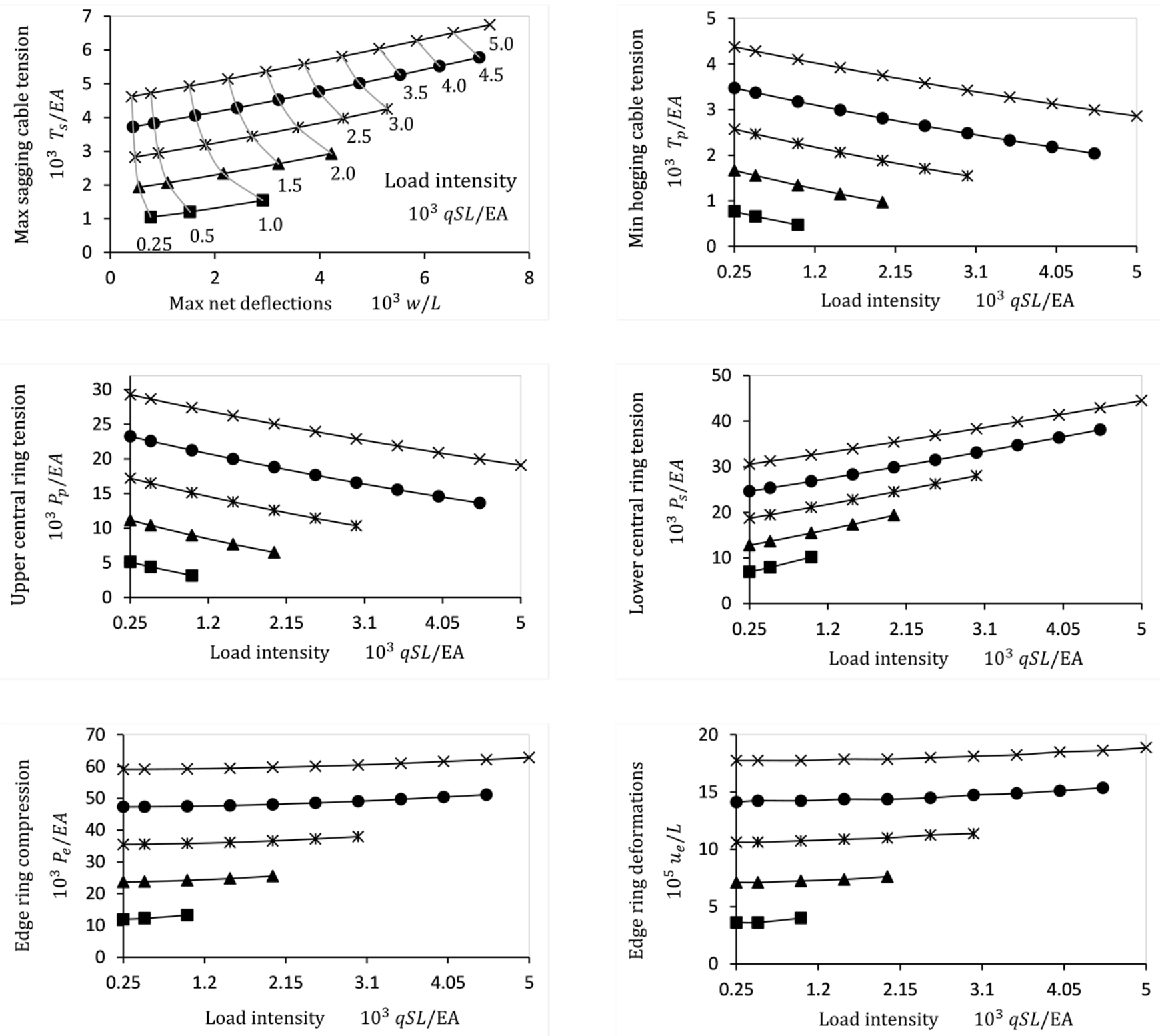

Fig. 47. Response of the convex cable roof beams, for sag/rise to span ratio $f=4 \% L$, load intensity $q S L E A=0.25 \times 10^{-3}$ to $5 \times 10^{-3}$, pretension force $H / E A=$ $1 \times 10^{-3}$ to $5 \times 10^{-3}$, and edge ring rigidity $E e A e / E A=167$.
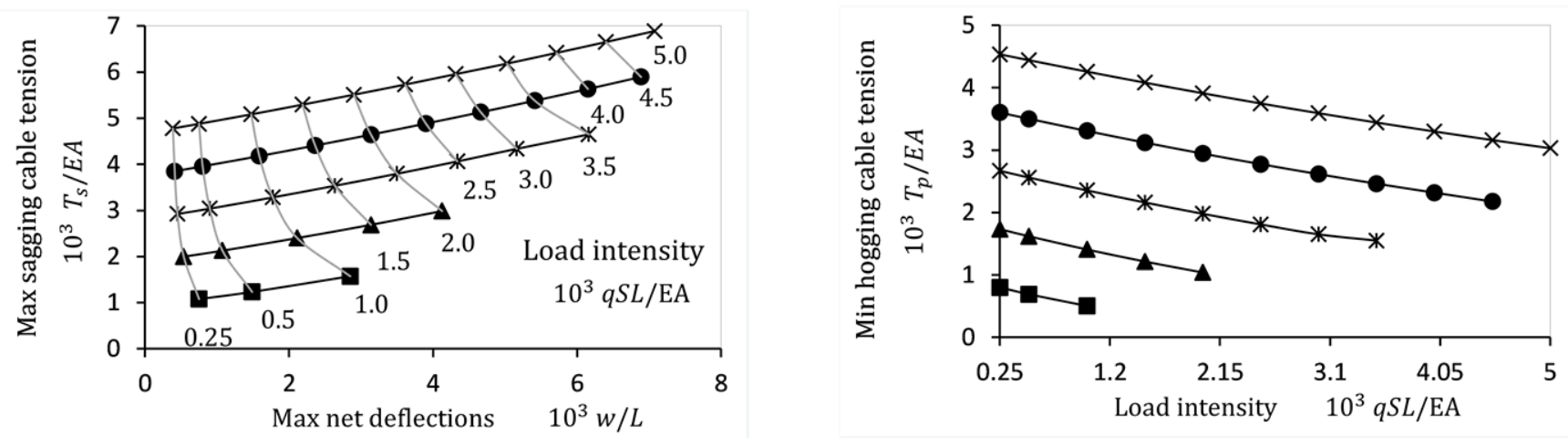

Fig. 48. Response of the convex cable roof beams, for sag/rise to span ratio $f=4 \% L$, load intensity $q S L E A=0.25 \times 10^{-3}$ to $5 \times 10^{-3}$, pretension force $H / E A=$ $1 \times 10^{-3}$ to $5 \times 10^{-3}$, and edge ring rigidity $\mathrm{Ee} A \mathrm{e} / E A=250$. 

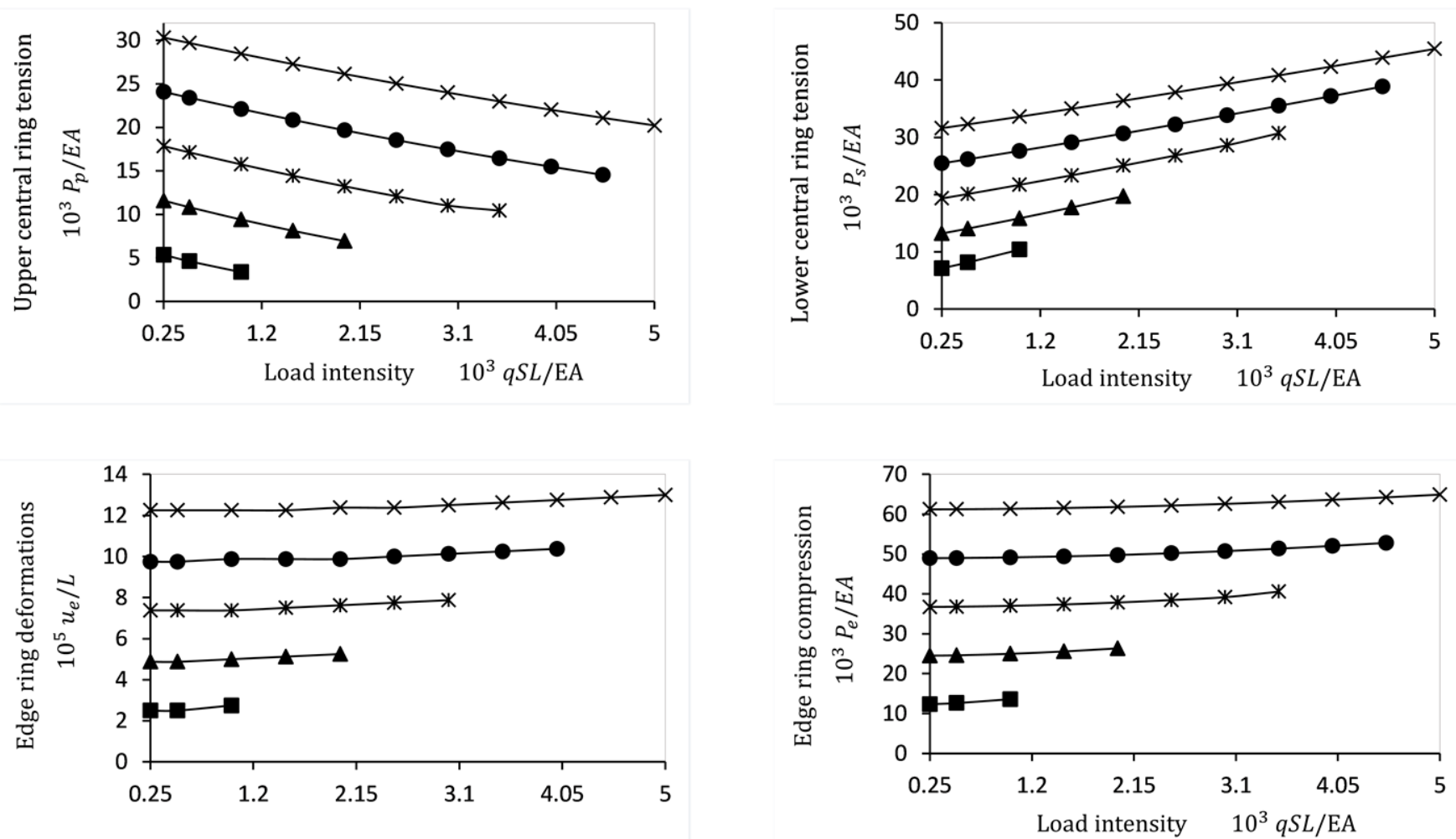

Fig. 48. Continued
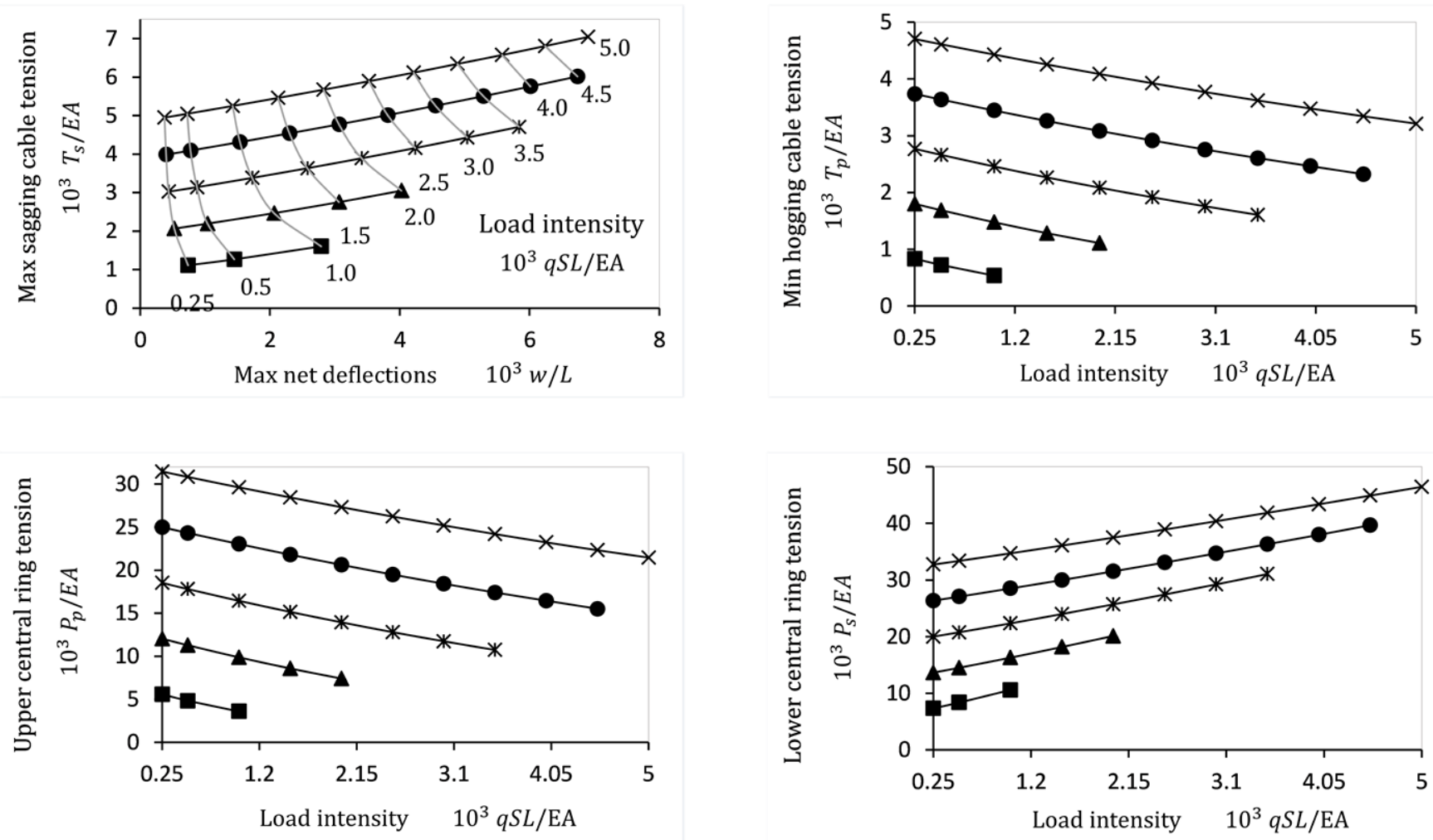

Fig. 49. Response of the convex cable roof beams, for sag/rise to span ratio $f=4 \% L$, load intensity $q S L E A=0.25 \times 10^{-3}$ to $5 \times 10^{-3}$, pretension force $H / E A=$ $1 \times 10^{-3}$ to $5 \times 10^{-3}$, and edge ring rigidity $E e A e / E A=500$. 

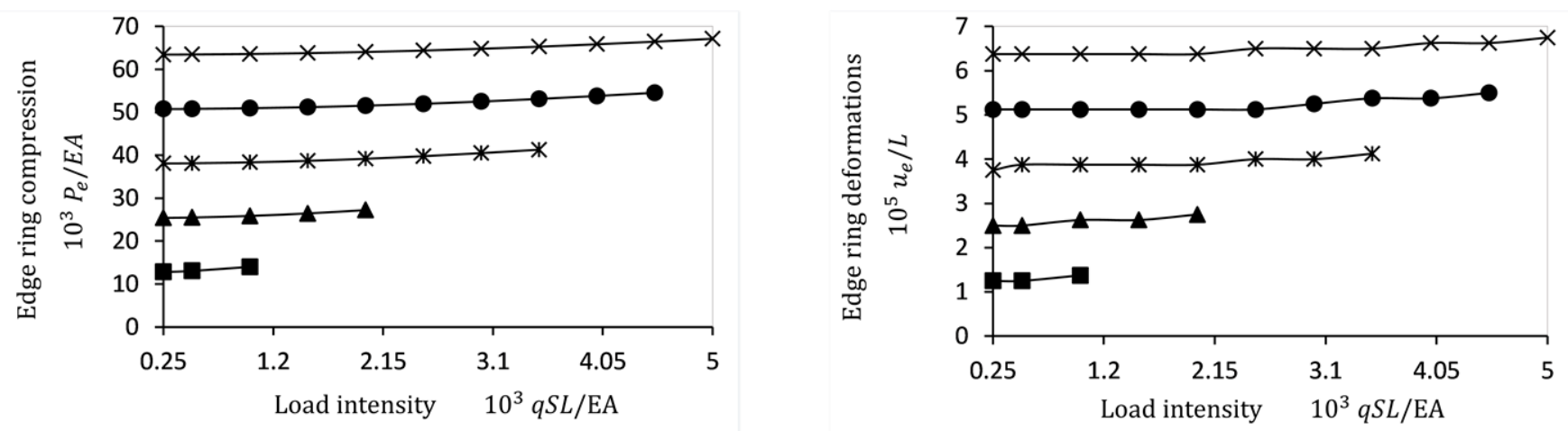

Fig. 49. Continued

\section{SYMMARY AND CONCLUSION}

This paper includes a study of the response of cable systems with deformable supports to present a preliminary analysis approach that has been examined and verified. It may be concluded that:

1. The stiffness of the sagging cables and curvature of hogging cables have a significant effects.

2. Although preliminary methods and simplifications that impose the supports of cable nets are infinite rigid give reasonable results. The stiffness of the edge ring must be included in the analysis.

3. It is essential to carry out a geometrically nonlinear static analysis in order to efficiently design cable structures, since the nonlinear behavior of the cables greatly affects the response of the rings which consequently behave in nonlinear manner.

\section{NOTATIONS}

$q=$ Equivalent load intensity per unit area due to any load combination (dead, live, wind, ...., etc.)

$q_{s}=q \times S$ The maximum load intensity per meter run on a cable beam.

$L=$ the roof diameter.

$l=$ central ring diameter.

$\delta=l / L=$ the diameters ratio.

$N=$ number of convex cable beams.

$S=$ span between convex cable beams $=\pi \times L / N$.

$f_{p}=$ hogging cable rise.

$f_{s}=$ sagging cable sag.

$H_{p}=$ hogging cable pretension force.

$H_{s}=$ sagging cable pretension force.

$E_{p} A_{p}=$ extensional rigidity of hogging cable.

$E_{s} A_{s}=$ extensional rigidity of sagging cable.

$E_{v} A_{v}=$ extensional rigidity of separator struts.

$E_{r} A_{r}=$ extensional rigidity of central rings.

$E_{e} A_{e}=$ extensional rigidity of the edge ring.

$E_{c} A_{c}=$ extensional rigidity of columns.

$\mathrm{MN}=$ Mega Newton.

\section{REFERENCES}

[1] H. T. Thai and S. E. Kim, "Nonlinear static and dynamic analysis of cable structures," Finite elements in analysis and design, vol. 47, no. 3, pp. 237-246, 2011.

[2] W. J. Lewis, M. S. Jones, and K. R. Rushton, "Dynamic relaxation analysis of the non-linear static response of pretensioned cable roofs," Computers \& Structures, vol. 18, no. 6, pp. 989-997, 1984.

[3] E. Coarita and L. Flores, "Nonlinear analysis of structures cable-truss," International Journal of Engineering and Technology, vol. 7, no. 3, pp. $160,2015$.

[4] C. C. Lai, "Static analysis of prestressed cable networks," Ph.D. thesis, Dept. Civil Eng., Kansas State Univ., Manhattan, Kansas, 1973.

[5] Y. M. Desai and S. Punde, "Simple model for dynamic analysis of cable supported structures," Engineering Structures, vol. 23, no. 3, pp. 271$279,2001$.

[6] J. S. Gero, "The preliminary design of cable network structures," Structures Report SR9, University of Sydney, 1975.

[7] W.J. Lewis, "Introduction," in Tension structures: form and behavior, London: Thomas Telford, 2003, pp. 1-20.

[8] I. Talvik, "The finite element modeling of cable networks with flexible support," Computers and Structures, vol. 79, pp. 2443-2450, 2001.

[9] M. Majowiecki and F. Zoulas, "The elastic interaction between the rope net and space frame anchorage structures," in Proc. the International Conference of Space Structures, 1984, pp. 778-784.

[10] J. Szabó, L. Kollár, and M. V. Pavlovic, Structural design of cable suspended roofs, England: Howard Limited, 1984.

[11] I. Vassilopoulou and C.J. Gantes, "Cable nets with elastically deformable edge ring," International Journal of Space Structures, vol. 20 , no. 1, pp. 15-34, 2005.

[12] M. Naguib, S. El Bagalaty, and S. Selim, "Optimum design of concave cable roofs," Mansoura Engineering Journal, vol. 21, no. 1, 1996.

[13] SAP2000, CSI Analysis Reference Manual, Computer and Structures, Berkeley, 2010.

[14] K. SANTOSO, "Wide-span cable structures," Ph.D., Thesis, Dept. Civil and Environmental Eng., Massachusetts Institute of Technology, Cambridge, Massachusetts, 2004.

[15] P. Krishna, "Analysis of pretensioned cable systems," in Cablesuspended roofs, New York: McGraw-Hill Companies, 1978 pp. 55-115.

[16] A. Pintea, and G. Tarta, "Comparison between the linear and nonlinear responses of cable structures II-dynamic loading," Procedia. Engineering, vol. 40, pp. 375-380, 2012.

[17] M. Mohie-Eldin, M.S. thesis, "Static and dynamic analysis of circular cable suspended roofs," Dept. Civil. Eng., Mansoura Univ., Egypt, 2003.

[18] I. Vassilopoulou, F. Petrini, and C.J. Gantes, "Nonlinear Dynamic Behavior of Cable Nets Subjected to Wind Loading," Elsevier. Structures, vol. 10, pp. 170-183, 2017.

[19] L.A. Kloiber, D.E. Eckmann, T.R. Meyer, and S.J. Hautzinger, "Design considerations in cable-stayed roof structures," Modern Steel Construction, vol. 44, no. 3, pp. 75-84, 2004.

[20] H.A. Buchholdt, "Cable beams and cable grids," in An introduction to cable roof structures, 2nd ed., London: Thomas Telford, 1999, pp. 182230.

[21] Standard Specification for Zinc-Coated Parallel and Helical Steel Wire Structural Strand, A586 - 04a, 2009. 